\title{
Role of the Heated Landmass on the Evolution and Duration of a Heavy Rain Episode over a Meiyu-Baiu Frontal Zone
}

\author{
Hiroyuki YAMADA, Biao GENG \\ Institute of Observational Research for Global Change (IORGC), Japan Agency for Marine-Earth Science and
} Technology (JAMSTEC), Yokosuka, Japan

Hiroshi UYEDA

Hydrospheric Atmospheric Research Center, Nagoya University, Nagoya, Japan IORGC, JAMSTEC, Yokosuka, Japan

and

Kazuhisa TSUBOKI

Hydrospheric Atmospheric Research Center, Nagoya University, Nagoya, Japan Frontier Research Center for Global Change, JAMSTEC, Yokohama, Japan

(Manuscript received 27 September 2006, in final form 28 June 2007)

\begin{abstract}
A series of numerical simulations on a heavy rain episode over a Meiyu-Baiu frontal zone was conducted, to demonstrate the role of the heated landmass over mainland China on the evolution and duration of the rainfall. The case studied here was a long-lived convective rainband, which formed over the Yangtze River basin, and brought heavy rainfall reaching $380 \mathrm{~mm}$ in 20 hours. The synoptic-scale situation was characterized by the indistinct meander of the upper-level flow, and the significant low-level southerly inflow from a subtropical high. Simulations using a cloud-resolving non-hydrostatic model were performed within a domain covering central and southern China, to reproduce land-surface heating to the south of the front. Sensitivity experiments without shortwave radiation, without terrain, and with modified land-surface conditions, were conducted to examine the factors effective in the evolution and duration of the rainband. The control simulation reproduced the rainband, and its reproducibility was good when compared to the observational evidence. The evolution resulted from the latent instability, due to the inflow of the warm and moist air from the fine-weather area to the south of the front. The rainband was not reproduced when the surface heating effect was excluded. The duration became short as the heated area was reduced, and was represented as a function of the meridional width of the heated area, and meridional velocity component in the lower troposphere. These results indicate that landsurface heating, over fine-weather areas to the south of the front, is a crucial factor for the rainband evolution and its duration.
\end{abstract}

Corresponding author: Hiroyuki Yamada, IORGC JAMSTEC, 2-15 Natsushima-cho, Yokosuka 2370061, Japan.

E-mail: yamada@jamstec.go.jp

(C) 2007, Meteorological Society of Japan

\section{Introduction}

Heavy rainfall is a principal severe weather phenomenon causing natural disasters, such as floods and landslides in East Asia. It is a major mission of meteorologists to clarify the mecha- 
nism of heavy rainfall, and to predict the occurrence and duration. It is well known that the Meiyu (or Baiu) season, between June and July, is a period in which local heavy rainfall frequently occurs. In the last 20 years, extensive floods occurred during the Meiyu seasons of 1991, 1998, and 2003, within the YangtzeHuai River basin of China. In many studies, it was noted that the floods resulted from a series of heavy rainfall events, related to the evolution of mesoscale convective systems (MCSs) over a Meiyu front (e.g., Akiyama 1984; Ding 1992; Ninomiya 2000). MCSs develop when atmospheric stratification over the front becomes latently unstable (Yamasaki 2005), owing to the inflow of warm and moist air (i.e., air of high equivalent potential temperature, $\theta_{e}$ ) from the south of the front in the lower troposphere (Chen et al. 1998; Yamada et al. 2003). The synoptic-scale flow surrounding an MCS is characterized by the presence of a low-level jet (LLJ) that transports the warm and moist air to the front (Ninomiya 2000). An MCS over this region is also characterized by diurnal variation; that is, an MCS tends to form in the late afternoon or evening (Takeda and Iwasaki 1987), and to maintain in the nighttime ( $\mathrm{Li}$ et al. 2007).

The frequent occurrence of heavy rainfall in the summer has been reported not only over mainland China but over the North American continent. Similar characteristics of heavy rain and MCS have also been reported in this area. The annual cycle of hourly precipitation, in excess of 1 inch $(25.4 \mathrm{~mm})$, over the eastern two-thirds of the United States, shows high frequency in the warm season, and peaks in July (Brooks and Stensrud 2000). MCSs are the cause of $74 \%$ of heavy rain episodes over the United States in the warm season (Schumacher and Johnson 2006). A southerly or southwesterly jet of warm and moist air in the lower troposphere is frequently observed to the south of the MCSs (Bosart and Sanders 1981; Schumacher and Johnson 2005). The nocturnal evolution of MCSs [including the mesoscale convective complex (MCC)] is also evident (Anderson and Arritt 1998; Laing and Fritsch 2000; Schumacher and Johnson 2006). The diurnal cycle of LLJ has also been reported (Trier and Parsons 1993; Augustine and Caracena 1994).
These similarities in the two continents suggest that there are some common mechanisms involved in the evolution of MCSs over the continental plain, especially in the nighttime. However, in both regions, little attention has been given to the origin of warm and moist air and its relevance to the nocturnal MCS evolution. With respect to the synoptic-scale flow, it is well known that warm and moist air is transported northward from tropical oceans by the anticyclonic flow of a subtropical highpressure system, such as a North Pacific high to the east of China, and a Bermuda high to the east of North America. In contrast, little is known about the importance of the continental surface on the MCS evolution through the supply of sensible and latent heat. Over mainland China, Shinoda and Uyeda (2002) recently noted the importance of paddy fields on the moistening of air in the lower troposphere. Although its contribution of the total precipitable water ( $15 \%$, according to Shinoda et al. 2005) was smaller than that from the oceans (about 67\%), what must not be forgotten here is the thermodynamic role for initiating deep convection. The accumulation of moisture (i.e., increase in $\theta_{e}$ ) near the surface can cause latent instability, which is a favorable condition on the MCS initiation.

Another point which has not been understood is the mechanism controlling the duration of MCSs and associated heavy rainfall. Although MCSs lasting a few days have been reported (Ninomiya et al. 1988; Bosart and Sanders 1981; Laing and Fritsch 2000), they are usually sustained by synoptic-scale upward motion, related to a short-wave trough. A noteworthy point is that MCSs can occur even in a location away from any short-wave trough. For example, in a case studied by Chen et al. (1998), heavy rainfall over China resulted from two MCSs that developed away from upper-level troughs, and remained for one day. They showed that the continuous supply of warm and moist air, due to a LLJ, contributed to the maintenance of latently unstable conditions, favorable for these MCSs. Ninomiya and Shibagaki (2003) also showed that MCSs can develop over a Meiyu front under a condition with no significant cyclonic flow in the middle or upper troposphere. These cloud systems usually last for, one day at most. However, factors 
controlling the duration of warm-moist air supply is not understood, despite their importance for the lifetime of these cloud systems.

After 20 June 2003, extensive flooding in the Yangtze-Huai River basin occurred as a result of a series of heavy-rain episodes over a onemonth period, with daily rainfall amount over $100 \mathrm{~mm}$. The accumulation in this period was a maximum of $897 \mathrm{~mm}$, which is comparable to the annual mean in this region (approximately $1,000 \mathrm{~mm}$ ). Our group conducted intensive field experiments, using Doppler radars in every Meiyu season since 2001 (Yamada et al. 2003; Geng et al. 2004), and succeeded in monitoring the evolution of MCSs during the heavy rain episodes of 2003. In a previous paper (Yamada et al. 2007, referred to hereafter as "Y07"), numerical simulations of a cloud cluster were conducted, based on the observational evidence. This study revealed the thermodynamic impact of the continental surface on the nocturnal evolution of this cluster through the generation of warm and moist air over the heated surface in the daytime, and latent instability over the front due to the inflow of this air. Although it is possible that this is the general process of the nocturnal MCS evolution over the continent, more case studies will be required to demonstrate its generality under various synoptic-scale conditions. In particular, it will be necessary to apply this idea to the nocturnal MCS evolution, under a no-trough environment.

The present study, thus, focuses on another MCS that developed under a synoptic-scale situation, different from Y07. This case is a longlived convective rainband, which formed in the afternoon of 4 July 2003, and brought heavy rainfall, reaching $380 \mathrm{~mm}$ for 20 hours, until the next afternoon. Observational data were analyzed, and numerical simulations were conducted, using a cloud-resolving nonhydrostatic model. These results are described in this paper. The main purpose of this study is to demonstrate the role of the heated landmass on the evolution and duration of the convective rainband. The importance of landsurface heating is demonstrated through not only a control simulation but also a sensitivity experiment without shortwave radiation, in the same way as for Y07. The relationship between the horizontal extent of the heated area and the duration of the rainband is examined through a series of sensitivity simulations with changed land-use distribution. In addition, the impact of the local topography on heavy rainfall is also examined because the potential effect of the topography (e.g., Dabie Mountains, between the Yangtze River, and the Huai River) was suggested in previous studies (e.g., Ding 1992). As in the case of $\mathrm{Y} 07$, the local standard time (LST: UTC+8) is used to represent the evolution with time because diurnal variation is an important factor.

\section{Model and observation}

The control simulation and sensitivity experiments of a convective rainband were conducted using a non-hydrostatic cloud-resolving model, while the observational data were used to show the mesoscale feature of the rainband, and to examine the reproducibility of simulation results. The details of the model and observation are described here.

\section{a. Control simulation}

As in the case of Y07, the Nagoya University Cloud Resolving Storm Simulator (CReSS, version 2.2, Tsuboki and Sakakibara 2002) was used for the numerical simulations in this study. This model was formulated on the basis of the non-hydrostatic and compressible equation system with terrain-following coordinates. The prognostic variables are three-dimensional velocity components, perturbations of pressure and potential temperature, subgrid-scale turbulent kinetic energy (TKE), and cloud physical variables. The cloud physics is explicitly formulated by a bulk method of cold rain with variables of mixing ratios and number densities of water substances. No convective parameterization scheme is included. Radiation processes are based on a scheme used in the Japan Spectral Model (Segami et al. 1989), which only considers the heat balance of the ground surface. The turbulence is parameterized by the 1.5 order closure with TKE. More details are provided in Wang et al. (2005).

The control simulation was conducted within doubly nested domains with horizontal grid spacing of $5 \mathrm{~km}$ (coarse mesh), and $2 \mathrm{~km}$ (fine mesh). The coarse mesh domain consists of $540 \times 370$ horizontal grids, and its location was the same as for Y07. The topography in and 

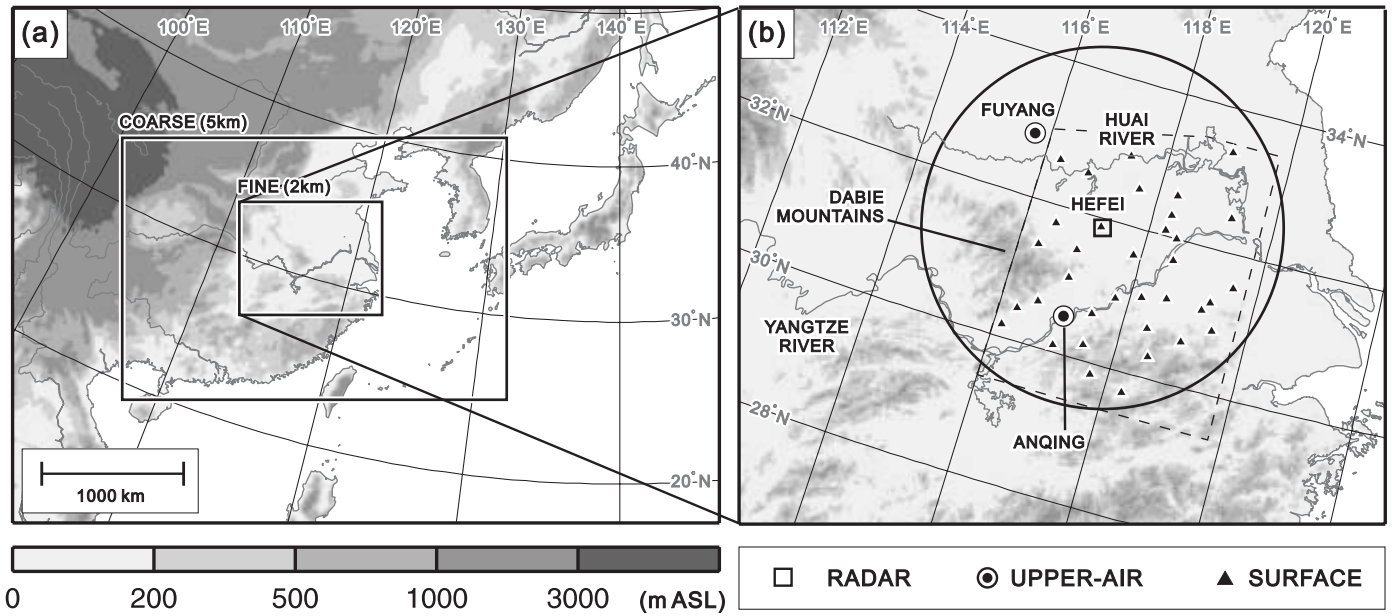

Fig. 1. (a) Topography in and around the model domain. Two rectangles show the domain of the coarse and fine mesh models. (b) Topography and location of the radar and weather stations in the fine-mesh model. A circle shows the $280-\mathrm{km}$ range of the Hefei Doppler radar. The area enclosed by a dashed line shows the surface-observational network.

around the model domains, shown in Fig. 1a, indicates that the coarse-mesh grids cover the plains and hills in central and southern China. In contrast, the fine mesh domain (Fig. 1b), consisting of $500 \times 400$ points, was moved $550 \mathrm{~km}$ southeastward from the one used in Y07, according to the location of the rainband. The vertical grids consist of 50 levels with an interval that stretches from 50 meters (near the sea surface) to 570 meters (near the top). The altitude of the highest plane is $19.7 \mathrm{~km}$ above sea level (ASL). The underground grids, which are used to represent the soil temperature, consist of 40 levels.

The initialization time is set to 0200 LST 4 July 2003, four hours before sunrise, to reproduce the surface heating and boundary layer, preceding the evolution of the rainband. The simulation continued for 36 hours (i.e., until 1400 LST 5 July). The initial fields and lateral boundary conditions were given using the sixhourly regional objective analysis dataset, provided by the Japan Meteorological Agency, with horizontal grid spacing of $20 \mathrm{~km}$. The surface temperature over the ocean was obtained from the optimum interpolation sea surface temperature (OISST, Reynolds et al. 2002). The altitude of the land surface was obtained from real topographic data (the global 30 arc-second elevation dataset: GTOPO30). The land-surface conditions were initiated homogeneously, by
Table 1. Surface parameters of two landuse categories used in the simulations.

\begin{tabular}{lcc}
\hline \hline & normal artificial \\
\hline $\begin{array}{l}\text { Albedo } \\
\begin{array}{l}\text { Evapotranspiration } \\
\text { efficiency }\end{array}\end{array}$ & 0.2 & 1.0 \\
$\begin{array}{l}\text { Roughness length } \\
\quad[\mathrm{m}]\end{array}$ & 0.5 & $0.4 \quad$ (for wind \\
velocity) \\
$\begin{array}{c}\text { Thermal capacity } \\
\quad\left[10^{6} \mathrm{Jm}^{-3} \mathrm{~K}^{-1}\right]\end{array}$ & $0.1 \quad \begin{array}{c}\text { (for scalar } \\
\text { variables) }\end{array}$ \\
$\begin{array}{c}\text { Thermal diffusivity } \\
{\left[10^{-7} \mathrm{~m}^{2} \mathrm{~s}^{-1}\right]}\end{array}$ & 2.3 & \\
\hline
\end{tabular}

assuming a land use of primarily paddy fields, in the same way as for Y07. This surface is hereafter referred to as the "normal" land-use, and the surface parameters are shown in Table 1. The land-surface parameters observed and modeled in the GAME-HUBEX ${ }^{1}$ project (Ikebuchi et al. 1998; Shinoda and Uyeda 2002) were taken into account to determine these parameters. The negative influence of the surface homogeneity upon the reproducibility of model re-

1 GEWEX Asian Monsoon Experiment/Huaihe River Basin Experiment, GEWEX: Global Energy and Water Cycle Experiment. 

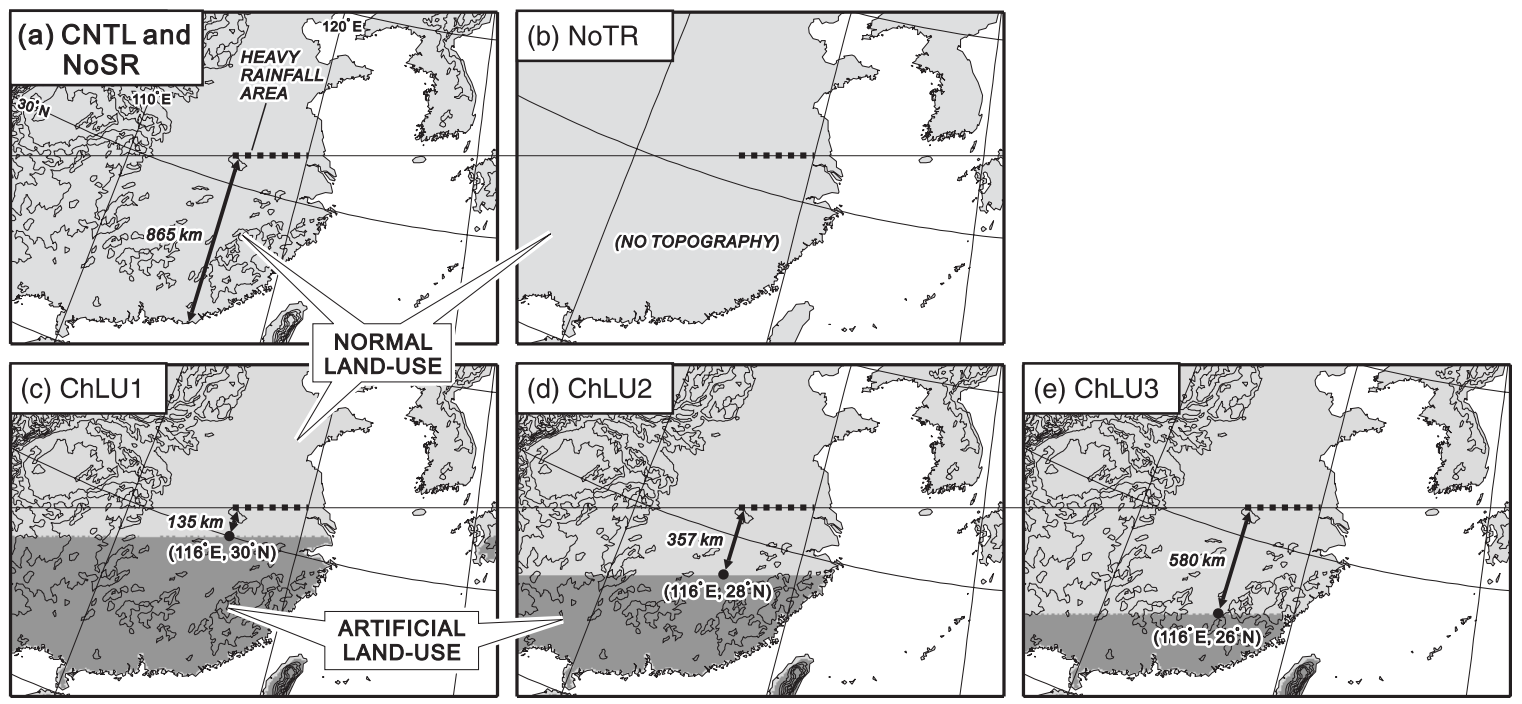

Fig. 2. Topography and land-use distribution of the control and sensitivity experiments. The contours of topography were drawn every $500 \mathrm{~m}$. The heavy rainfall area that is the focus of this study is indicated with a bold dashed line.

sults was negligibly small in the present case because the control simulation successfully reproduced the rainband (described in Section 4).

\section{b. Sensitivity experiments}

Three types of sensitivity experiments were performed, to examine the importance of the heated land surface on the evolution of the convective rainband. These experiments were conducted without shortwave radiation (hereafter, NoSR), without terrain (NoTR), and with modified land-use distributions (ChLU1, ChLU2, and ChLU3). The topography and land-use distribution in these experiments are shown in Fig. 2. The domains and initialization method, except for the land-surface conditions, were the same as those in the control experiment.

The NoSR experiment has the same topography and land-use distribution as the control one. The aim of the NoSR experiment was to demonstrate the importance of diurnal surface heating on the rainband evolution by excluding the heating effect. In CReSS, the net shortwave radiation at the surface is calculated from the following equation,

$$
\begin{aligned}
R S \downarrow= & \left(1-A_{l}\right) S \downarrow\left(1-0.7 C D_{L}\right)\left(1-0.6 C D_{M}\right) \\
& \times\left(1-0.3 C D_{H}\right)
\end{aligned}
$$

where $A_{l}$ is the albedo, $S \downarrow$ is the surface-level insolation under cloud-free conditions and $C D_{L}, C D_{M}$, and $C D_{H}$ are the effects of scattering and absorption due to clouds in the lower, middle, and upper troposphere, respectively. The NoSR simulation can be accomplished by altering this equation as follows,

$$
R S \downarrow=0 .
$$

This means that diurnal heating effects can be completely excluded, while both boundarylayer and surface physical processes can be considered in the same way as in the control simulations.

The NoTR experiment (Fig. 2b) has a homogeneous land-use and a flat topography; namely, the altitude of all land areas was set to $0 \mathrm{~m}$ ASL. This experiment can exclude the effect of the topography upon the evolution of the rainband and its location. Thus, the NoTR experiment was used to clarify the principal factor in the stagnancy of the rainband, which is sometimes a key point on the occurrence of local heavy rainfall. Since this experiment was initialized using the reanalysis data, grid points under the real topography in the initial fields contain values estimated from the variables on the ground.

In the series of ChLU1-3 experiments, an "artificial" land-use category was used, as well 
as the normal land-use. The parameters of the artificial land surface, shown in Table 1, are characterized by an extremely high albedo (1.0), which sets $R S \downarrow$ of Eq. (1) to zero (i.e., complete reflection of solar radiation), and produces no surface heating in the daytime. The reflected upward shortwave never cause heating in the atmosphere because this effect has not been included in CReSS. Thus, the use of the artificial surface makes it possible to deliberately modify the area where the land surface is heated by insolation. These experiments were intended for an examination on the dependence of the rainfall duration upon the horizontal extent of the heated area. The land-use distribution in the ChLU1-3 experiments is shown in Figs. 2c-e. The artificial surface covers the southern part of the continent, to modify the horizontal extent of the heated area on the southern side of the front. The meridional width between the southern boundary of the normal surface and the heavy-rainfall area was $135 \mathrm{~km}$ in the ChLU1 experiment, while it was $580 \mathrm{~km}$ in the ChLU3.

\section{c. Observational data}

As in the case of Y07, the radar reflectivity, and upper- and surface-meteorological data, collected by an intensive field experiment, under the cooperative project between the Japan Agency for Marine-Earth Science and Technology (JAMSTEC), and the China Heavy Rainfall Experiment and Study (CHeRES), were used in this study. This experiment consisted of Hefei S-band Doppler radar, two upper-air observational stations, and a surface observation network consisting of 32 stations (see Fig. 1b). The details are described in Yamada et al. (2003).

The reflectivity data were collected every 5 minutes by the radar's three-dimensional scan (i.e., volume scan), consisting of 14 elevation steps from $0.2^{\circ}$ to $20.0^{\circ}$. Raw data were interpolated onto a grid volume in the spherical coordinates (longitude, latitude, altitude) using a Cressman-type weighted interpolation technique. The grid spacing was $0.02^{\circ}$ in the two horizontal directions, and $1.0 \mathrm{~km}$ in the vertical direction from the lowest plane of $1.0 \mathrm{~km}$ ASL. Upper-air observations were carried out every 6 hours at the Fuyang and Anqing stations. At the surface stations, the wind speed and direc- tion, pressure, temperature, dew-point temperature, and rainfall amount were collected every hour. In addition to these data, infrared and visible images of the Geostationary Operational Environmental Satellite (GOES-9), and the daily amount of rainfall collected operationally in Anhui Province, were also used.

\section{Case overview}

The heavy rainfall under investigation, occurred in Anhui Province, from the evening of 4 July through the afternoon of the next day. The overall features, mesoscale characteristics, and synoptic-scale situations of the heavy rain episode are described.

\section{a. Overall features}

The horizontal distribution of the 48-hour accumulated rainfall in Anhui Province, from 08 LST 4 July, is shown in Fig. 3a. A zonal belt of rainfall, exceeding $50 \mathrm{~mm}$, extended to the east-northeast of the Dabie Mountains, and the peak was $382 \mathrm{~mm}$ at Chuzhou (58236 of the station code). The series of hourly rain at this station (Fig. 3b), shows that most of the rainfall (380 mm) occurred within 20 hours from 18 LST of 4 July through 14 LST of the next day.

The evolution of cloud systems and the surface pressure distribution from the model initialization is demonstrated using a series of satellite infrared images with a surface weather chart, as shown in Fig. 4. The period of simulations (described in Sections 4 and 5) corresponds between Figs. $4 \mathrm{a}$ and d. Within the intensive observational area, a front remained until 02 LST 6 June (i.e. Figs. 4a-e). Cloud bands over the front were characterized by lower cloud-top black-body temperature $\left(T_{B B}\right)$ on the southern side, and higher $T_{B B}$ on the northern side, suggesting the presence of deep convection in the southern part of the band. It is noteworthy that a vast area of $T_{B B}$ higher than $-10^{\circ} \mathrm{C}$ extended to the south of the frontal cloud band until 02 LST 6 July. In the satellite visible images in 08-16 LST (not shown), the area of high $T_{B B}$ corresponded to the area in which albedo was continuously lower than 0.3 , suggesting a fine weather condition. According to Y07, a fine-weather area on the southern side of the front can play a role in the formation of warm and moist air.

During the heavy rain episode (Figs. $4 c-d$ ), a 

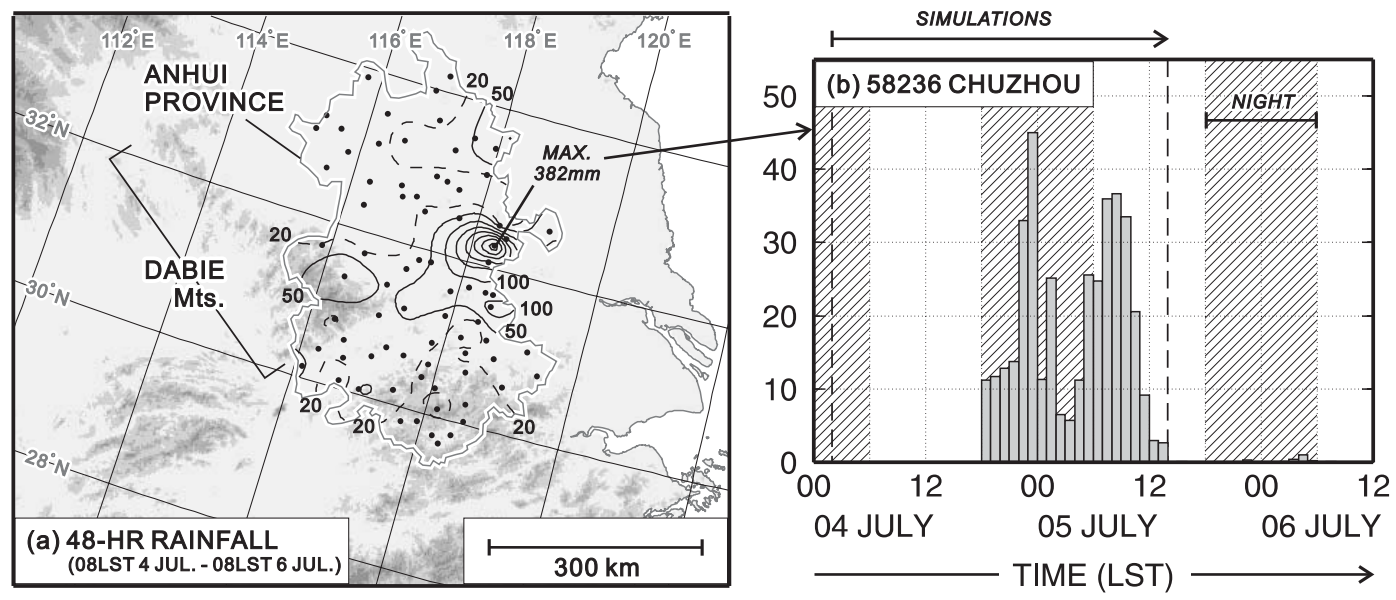

Fig. 3. (a) Distribution of the 48-hour accumulated rainfall. (b) Series of the hourly rainfall observed at the Chuzhou meteorological station.

deep cloud systems $\left(T_{B B} \leq-70^{\circ} \mathrm{C}\right)$ developed over the front within the observational area. A surface depression simultaneously started to develop below the deep cloud system. This depression propagated along the front, at a speed $\left(2.5 \mathrm{~ms}^{-1}\right)$ slower than that of upper-level cloud shields (nearly $10 \mathrm{~ms}^{-1}$ ), until 02 LST 6 July (Figs. 4b-d).

\section{b. Mesoscale characteristics}

Changes in the mesoscale characteristics before and after the evolution of the deep cloud system within the radar observational area, are shown in Fig. 5. In the daytime (Fig. 5a), a band echo with weak reflectivity ( $\leq 40 \mathrm{dBZ}$ ), corresponding to the frontal cloud band, was in the northern half of the radar circle. To the south of the band echo, the area of equivalent potential temperature higher than $356 \mathrm{~K}$ (hereafter, high $\theta_{e}$ ) extended. This area corresponds to the high $T_{B B}$ shown above, suggesting that the high- $\theta_{e}$ air originated from a fineweather area. It is noteworthy that a shearline (marked by a dotted line) between southerly and northerly winds lay on the eastern side of the Dabie mountains. In the nighttime (Fig. $5 \mathrm{~b}$ ), the weak band was replaced by a convective rainband, with strong reflectivity cores $(\geq 45 \mathrm{dBZ}$ ). This rainband corresponds to the deep cloud system, shown in the satellite image (Fig. 4c), and was the cause of the heavy rainfall. This rainband located just on the north of the shearline, and the high- $\theta_{e}$ area still remained to the south of the rainband.

The time-latitude section of reflectivity at $3.0 \mathrm{~km} \mathrm{ASL}, \theta_{e}$ at the surface, and the wind barbs over the upper-air stations at $950 \mathrm{hPa}$, are shown in Fig. 5c. The reflectivity and surface $\theta_{e}$ were averaged zonally within $0.5^{\circ}$ width; in other words, lines $\mathrm{A}-\mathrm{B}$ and $\mathrm{C}-\mathrm{D}$ correspond to the strips in Figs. 5a and b, respectively. High reflectivity ( $\geq 40 \mathrm{dBZ}$ ) of the convective rainband appeared at first on 17 LST about $1^{\circ}$ south of the preexisting weak band. This band remained near $32^{\circ} \mathrm{N}$ until the next morning (10 LST), and then moved southward. Its duration (more than 21 hours) was much longer than that of the case studied in Y07, which also developed in the late afternoon but dissipated before the morning (Fig. 3 of Y07). Figure 5c clearly shows that the shearline lay on the southern side of the convective rainband throughout the heavy rain episode. It is noteworthy that the high- $\theta_{e}$ area also remained during this episode, even after midnight. This means that high- $\theta_{e}$ air was continuously supplied from the south, and contributed to the long-lasting heavy rain episode.

The vertical thermodynamic features over the high $-\theta_{e}$ area are described, using the profile over Anqing at 14 LST 4 July (Fig. 6a). The high- $\theta_{e}$ air $(\geq 356 \mathrm{~K})$ near the surface caused latently unstable stratification, favorable for the evolution of a deep convective updraft. The 


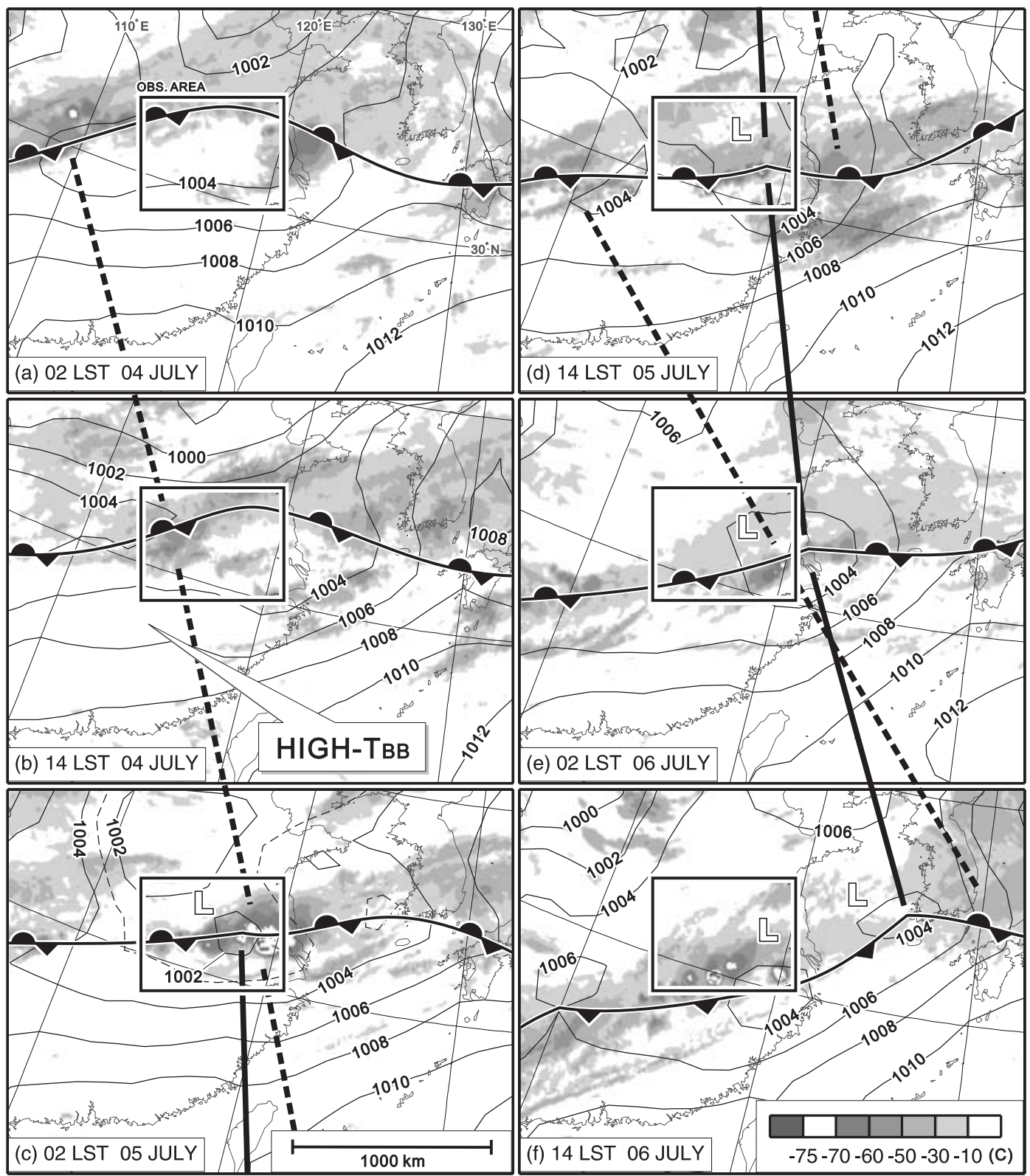

Fig. 4. Series of cloud-top black-body temperature $\left(T_{B B}\right)$ with a surface weather chart every 12 hours within the coarse-mesh model domain. Contours of the pressure are drawn every $2 \mathrm{hPa}$. Bold solid and broken lines show the movement of a frontal depression and cloud systems, respectively. A rectangle in each panel corresponds to the field experimental area shown in Fig. 5.

highest $\theta_{e}$ was $359.8 \mathrm{~K}$ at the surface, and had the potential to rise to the level of neutral buoyancy (LNB) at $13.9 \mathrm{~km}$ ASL after being uplifted to the level of free convection (LFC) at $1.9 \mathrm{~km}$ ASL. The convective available potential energy (CAPE) for the highest $\theta_{e}$ was $1637 \mathrm{~J} \cdot \mathrm{kg}^{-1}$, which increased from $1094 \mathrm{~J} \cdot \mathrm{kg}^{-1}$ with LFC at $3.6 \mathrm{~km}$ ASL at $08 \mathrm{LST} 4$ July, indicating significant destabilization in the daytime. The wind at $1.0 \mathrm{~km}$ ASL was southwesterly of $10 \mathrm{~ms}^{-1}$, and responsible for the horizontal inflow of high- $\theta_{e}$ air to the front in the lower troposphere. There were two local maxima of the low-level southwesterly inflow 


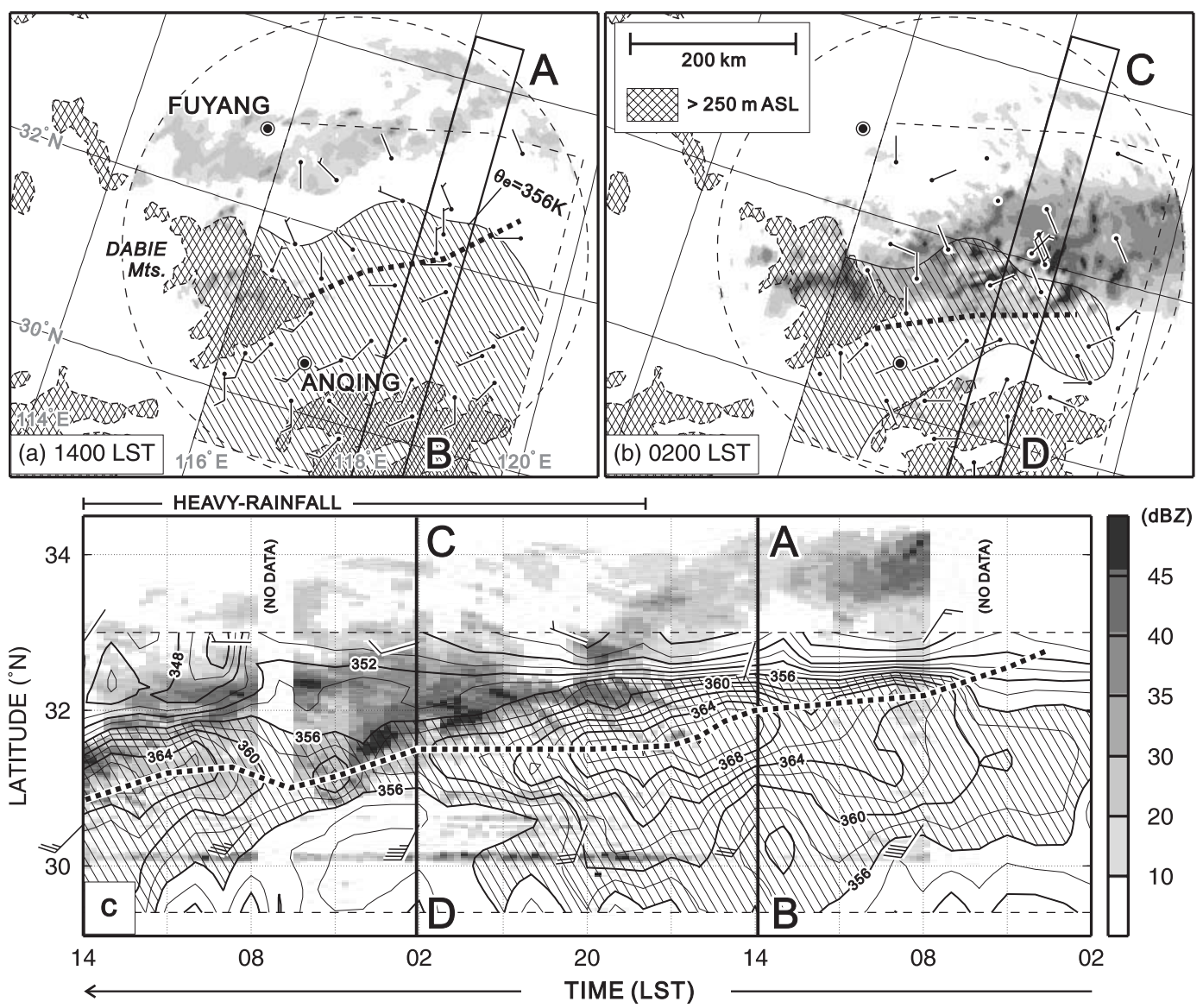

Fig. 5. (a and b) Radar reflectivity at $3.0 \mathrm{~km} \mathrm{ASL}$ and wind barb at the surface on 1400 LST 4 July and 0200 LST 5 July. Half and full barbs indicate 2 and $4 \mathrm{~ms}^{-1}$, respectively. Bars without bars indicate wind weaker than $2 \mathrm{~ms}^{-1}$. The area where equivalent potential temperature at the surface was larger than $356 \mathrm{~K}$ is hatched. Mountains higher than $500 \mathrm{~m}$ ASL are cross-hatched. A dotted line means a shear line. (c) Time-latitude section of the radar reflectivity $(3.0 \mathrm{~km}$ ASL) and wind barbs at $925 \mathrm{hPa}$. The direction of the time axis is toward the left.

at $0.3 \mathrm{~km}$ ASL $\left(13 \mathrm{~ms}^{-1}\right)$ and $3.0 \mathrm{~km} \mathrm{ASL}$ $\left(21 \mathrm{~ms}^{-1}\right)$. The time-height cross section of $\theta_{e}$ and wind for three days after 3 July (Fig. 6b) shows that the latently unstable condition due to the presence of high- $\theta_{e}$ air in the lower troposphere lasted three days. In particular, LFC descended from $4 \mathrm{~km}$ ASL at 08 LST 4 July to $2 \mathrm{~km}$ at $14 \mathrm{LST}$, and remained close to this level for one day until 14 LST 5 July. This is a suitable condition for the maintenance of the convective rainband.

\section{c. Synoptic situations}

Changes in the synoptic-scale conditions, from the model initialization time through 18 hours later, are described using the reanalysis data shown in Fig. 7. The geopotential heights at $500 \mathrm{hPa}$ (Fig. 7a) show that there was a trough near $135^{\circ} \mathrm{E}$, and there was no marked meandering of a westerly jet over eastern China. Although another weak and small trough located near the eastern rim of the Tibetan Plateau at 02 LST, it had almost disappeared by 20 LST. The distributions of vertical velocity show that an area of upward motion near $120^{\circ} \mathrm{E}$ at $02 \mathrm{LST}$ became weak until 20 LST. The geopotential heights at $925 \mathrm{hPa}$ (Fig. 7b) show that eastern China was situated in the trailing portion of a sub-synoptic-scale depression near $135^{\circ} \mathrm{E}$, and there was no depression over eastern China during this period. Such a situation without a trough is similar to 

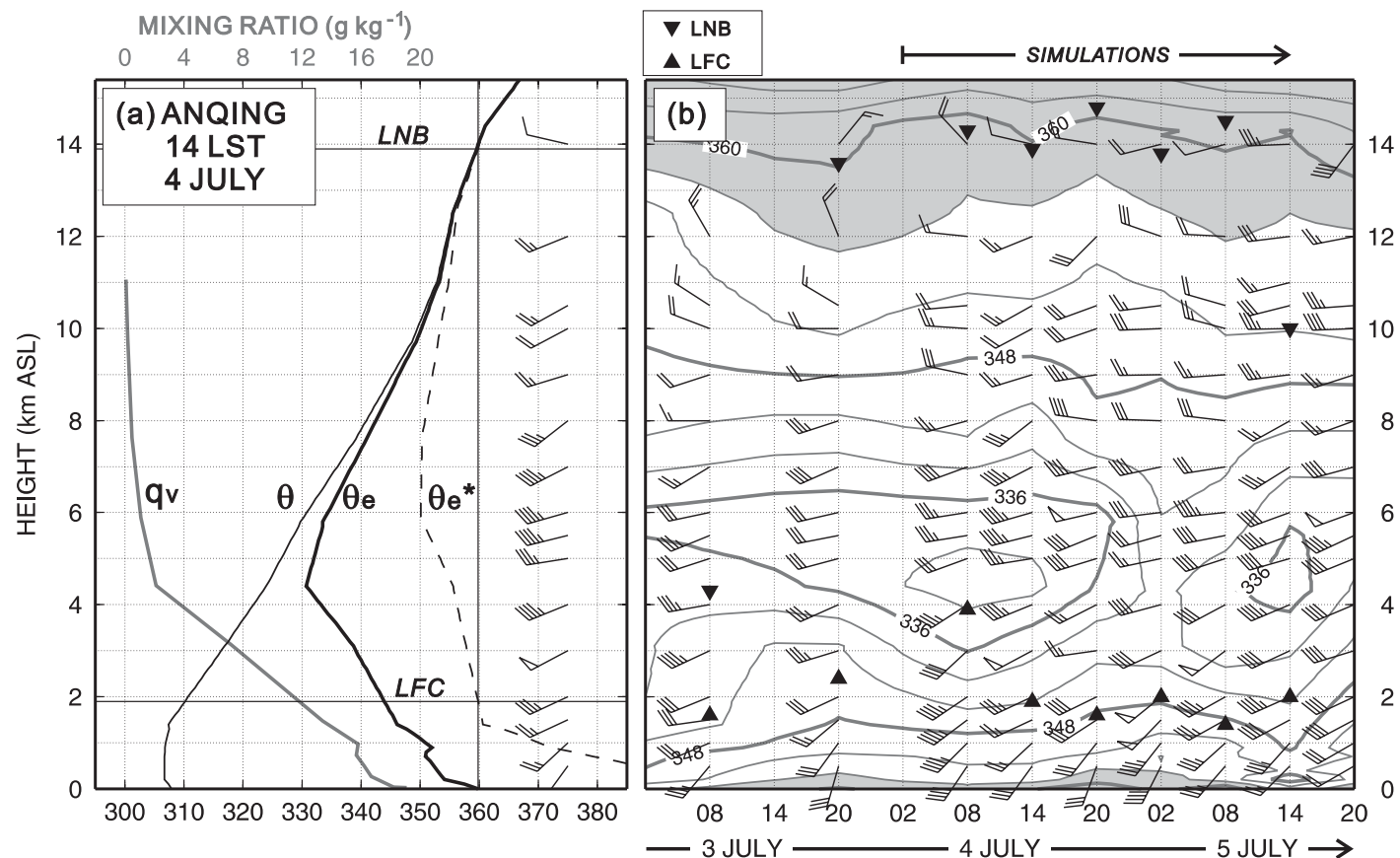

Fig. 6. (a) Vertical profile of the vapor mixing ratio $\left(q_{v}\right)$, potential temperature $(\theta)$, equivalent potential temperature $\left(\theta_{e}\right)$, saturated equivalent potential temperature $\left(\theta_{e}^{*}\right)$, and wind barb observed at Anqing (see Fig. 5) on 14 LST 4 July. A pennant indicates $20 \mathrm{~ms}^{-1}$, while barbs are drawn in the same manner as in Fig. 5. (b) Time-height section of equivalent potential temperature and wind barb observed every 6 hours at Anqing. The levels of free convection (LFC) and neutral buoyancy (LNB) are superimposed.

the environment of meso- $\alpha$-scale cloud systems studied by Ninomiya and Shibagaki (2003), which seems to be favorable for the stagnation of a Meiyu front, as well as for the long duration of a local heavy rain episode. The absence of a depression or trough at the 925 and $500 \mathrm{hPa}$ levels, means that the generation of the surface depression (shown in Figs. 4c-f) was not related to any synoptic-scale disturbance in the middle and upper troposphere.

Another noteworthy point at $500 \mathrm{hPa}$ (Fig. $7 \mathrm{a})$ is the westward extension of a subtropical high over southern China, as recognized from the $5880 \mathrm{~m}$ contour of the geopotential height. This extension suggests the prevalence of subsidence, which suppresses the development of convective clouds and maintains the fineweather conditions to the south of the front, as shown in the satellite imagery. The distributions of $\theta_{e}$ at $925 \mathrm{hPa}$ (Fig. 7b) show that an area of $\theta_{e}$ larger than $352 \mathrm{~K}$, extended remarkably in 18 hours on the southern side of the front. A marked change is also seen in the distributions of latent stability (Fig. 7c), estimated between 925 and $600 \mathrm{hPa}$. An area of negative value (meaning latent instability) expanded rapidly on the southern side of the front. The synoptic-scale low-level flow over China is characterized by the southerly inflow to the front (Fig. 7c). This evidence suggests that the heating of the low-level southerly inflow over China in the daytime was responsible for the rapid extension of the areas of high $\theta_{e}$ and latent instability.

In summary, observational evidence showed that a heavy rain episode of 20 hours resulted from a long-lasting convective rainband over a stationary front. The synoptic-scale situations were characterized by the presence of a southerly inflow in the lower troposphere, and the absence of a trough in the middle and upper troposphere. The vast area of fine weather to the south of the front, due to the prevalence of a subtropical high, is also important back- 
(a) $Z_{500}(\mathrm{~m}), \theta_{e 500}(\mathrm{~K}), \omega_{500}\left(\mathrm{hPa} \mathrm{hr}^{-1}\right)$

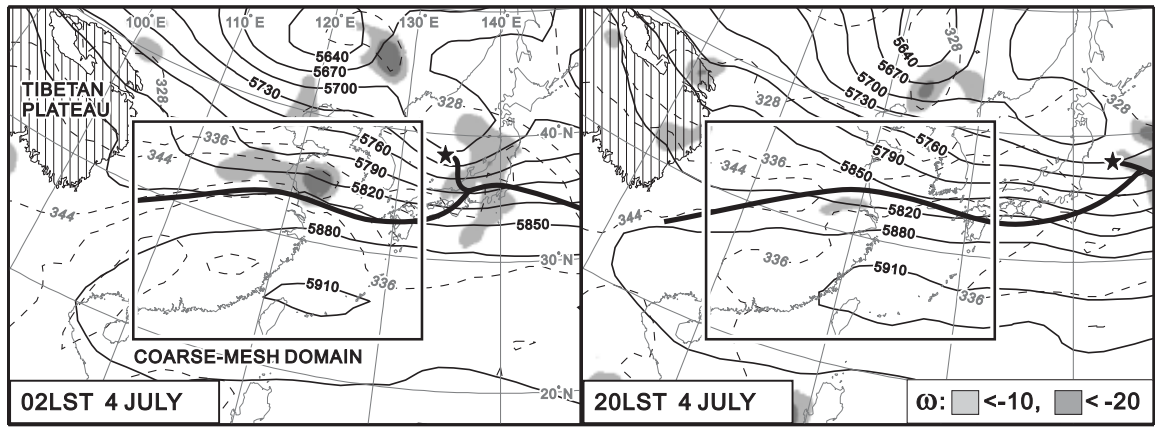

(b) $Z_{925}(\mathrm{~m}), \theta_{e 925}(\mathrm{~K})$

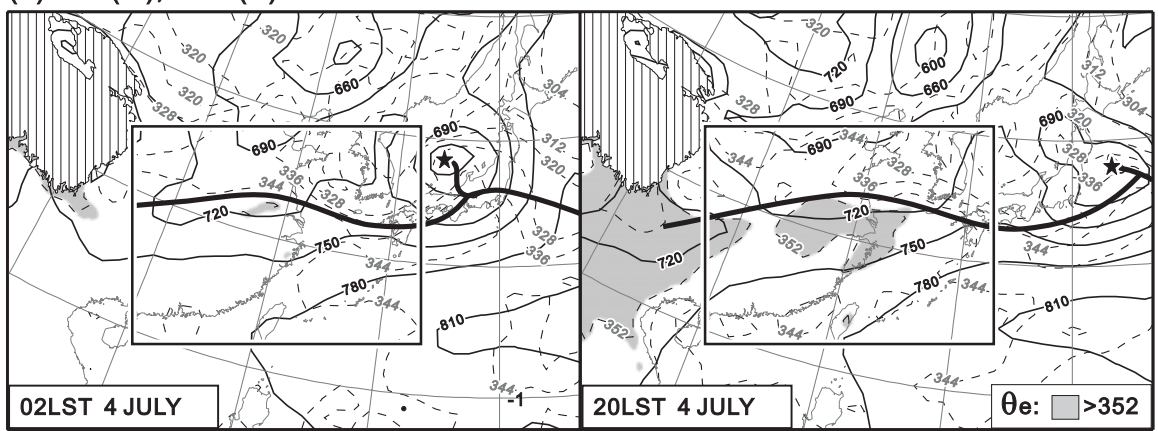

(c) $q V_{925}(\mathrm{~g} \mathrm{~kg} \mathrm{~m} \mathrm{~s})$, STABILITY $(\mathrm{K} 100 \mathrm{hPa})$

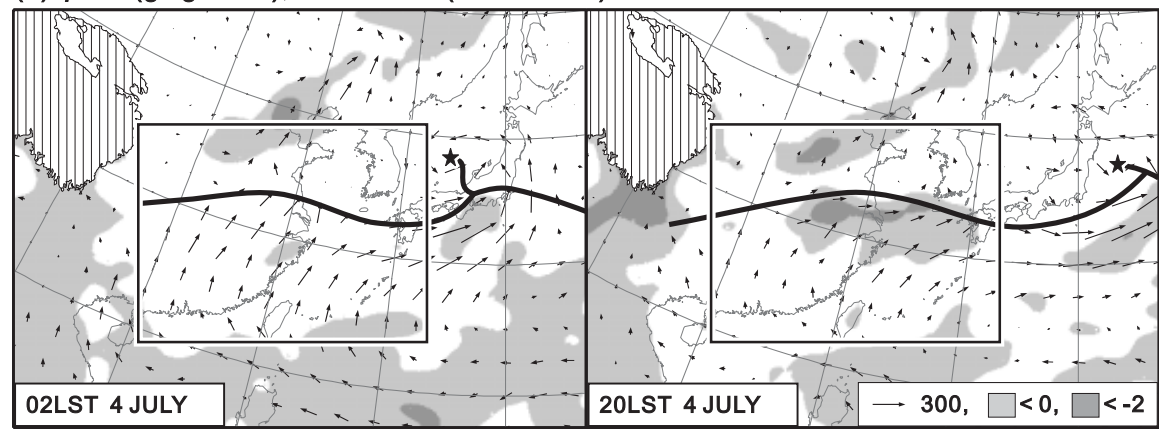

Fig. 7. Changes in the synoptic-scale conditions between 02 LST (left panel) and 20 LST (right panel). A star and bold line in each panel indicate the location of a depression and the MeiyuBaiu front at the surface, respectively. (a) Geopotential height (solid contour), equivalent potential temperature (broken contour), and vertical velocity (shades) at $500 \mathrm{hPa}$. (b) Geopotential height (solid contour) and equivalent potential temperature (contour and shades) at $925 \mathrm{hPa}$. (c) Vapor flux vectors at $925 \mathrm{hPa}$ and latent stability represented as $\left(-\left[\theta_{e}(925 \mathrm{hPa})-\theta_{e}^{*}(600 \mathrm{hPa})\right] / \Delta p\right.$, with the unit of $\mathrm{K} \cdot(100 \mathrm{hPa})^{-1}$.

ground. These features are different from those of the case studied in Y07, except for the latent instability due to the supply of high- $\theta_{e}$ air from the south. In other words, the formation of the high $\theta_{e}$ air in the daytime was probably key to the evolution of the rainband, as it was in the Y07 case. It is also suggested that the duration is related to the horizontal extent of the fine-weather area. The meridional width of this area (approximately $865 \mathrm{~km}$ ), in the present study, was wider than that (about $500 \mathrm{~km}$ ) of Y07.

\section{Control experiment}

Based on observational evidence, the description of the control experiment addresses the effect of high- $\theta_{e}$ air on the rainband evolution, as well as the reproducibility of the results 
CNTL (COARSE)

(a) SLP, RAIN

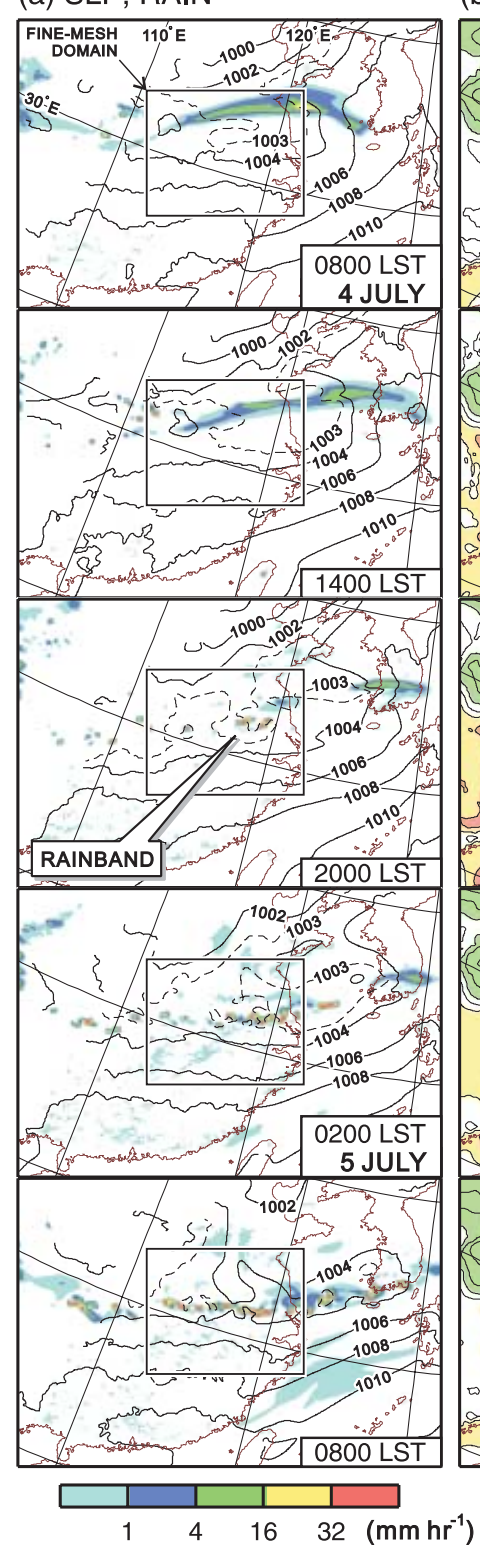

(b) $\theta \mathrm{e}(0.5 \mathrm{~km} \mathrm{AGL})$

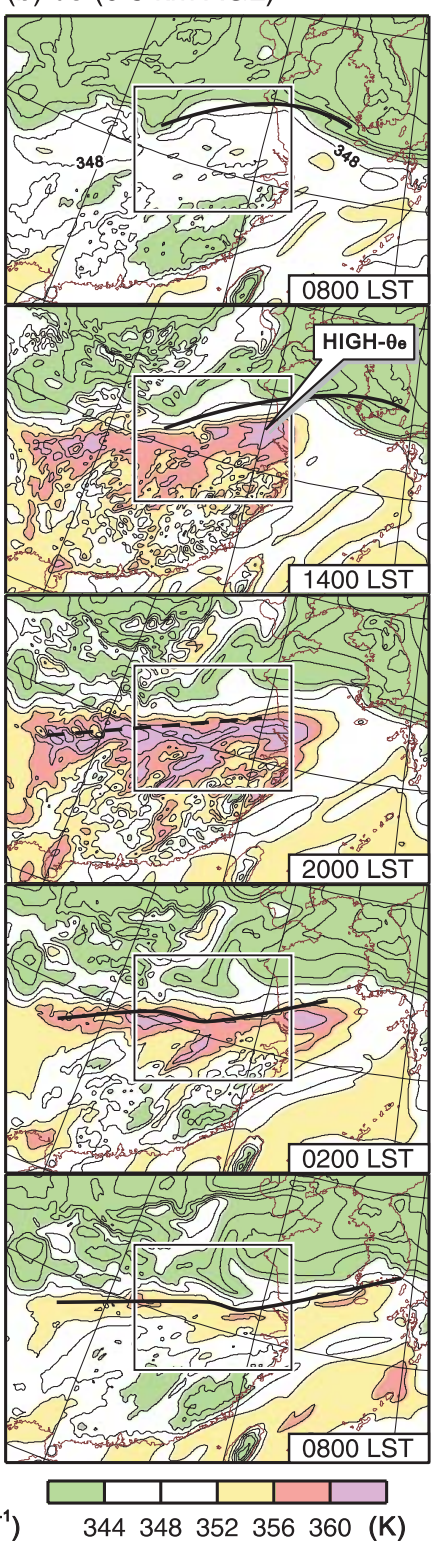

(c) UV (0.5 km AGL), FLUX

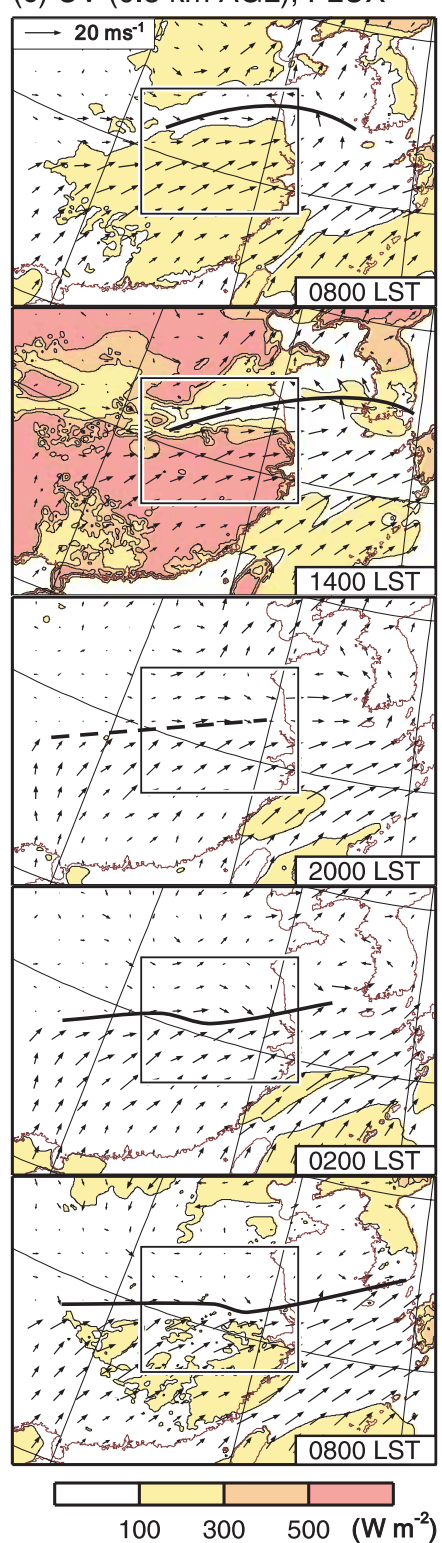

Fig. 8. Horizontal distributions of the coarse-mesh control experiment. (a) Rainfall intensity at the surface (shade) and sea level pressure ( $\mathrm{hPa}$, contour). Pressure contours are drawn in areas where the surface altitude is lower than $500 \mathrm{~m}$ ASL. (b) Equivalent potential temperature at $0.5 \mathrm{~km}$ AGL. (c) Wind vector at $0.5 \mathrm{~km}$ AGL and sum of the sensible and latent heat fluxes at the surface level.

through comparisons with the observational and reanalysis data. Figure 8 shows the overall evolution of the coarse-mesh control simulation at $0.5 \mathrm{~km}$ above the ground level (AGL), between 6 and 30 hours after the model initial- ization. The rainfall distributions (Fig. 8a) show that a band of weak rainfall in the finemesh domain at 1400 LST was replaced by one with cellular cores of heavy rainfall $\left(\geq 32 \mathrm{~mm} \mathrm{hr}^{-1}\right)$ after that. The latter (i.e., con- 


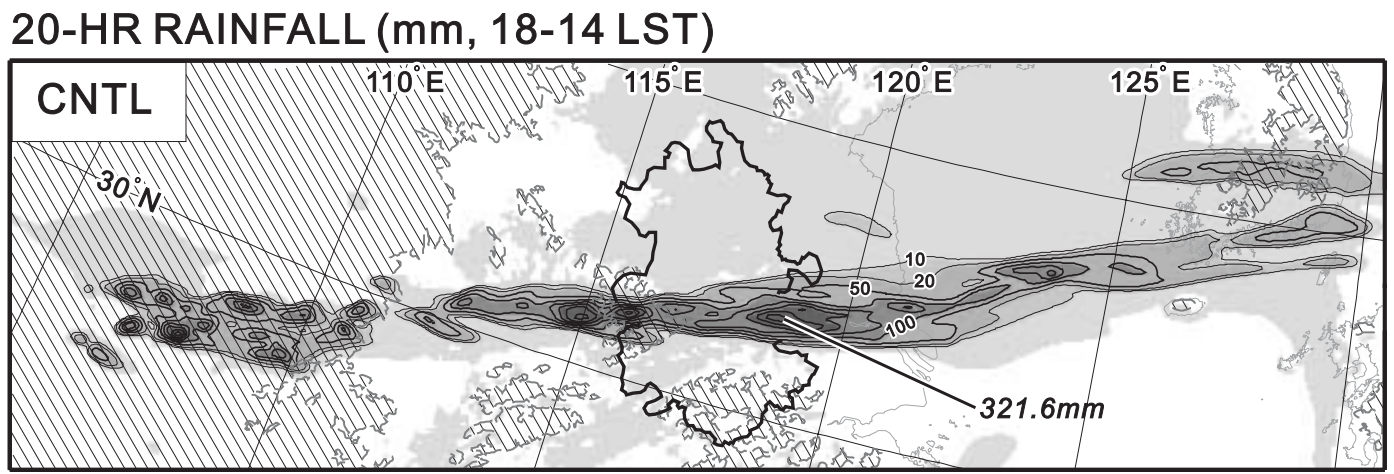

Fig. 9. Horizontal distribution of the amount of rainfall accumulated for 20 hours from 18 LST 4 July through 14 LST 5 July. Contours are drawn at 10, 20, and every $50 \mathrm{~mm}$. Shaded areas indicate mountains higher than $500 \mathrm{~m}$ ASL. The boundary of Anhui Province is drawn by a bold solid line.

vective rainband) developed in the nighttime, and remained in the next morning. The change in rainfall pattern is similar to that in the observed reflectivity pattern (i.e., Fig. 5). During the development, the sea-level pressure distribution showed the generation of pressure minima along the rainband by $0200 \mathrm{LST}$, which is roughly comparable with the pressure minima along the front, shown in Fig. 4c. The $\theta_{e}$ distributions (Fig. 8b) show that high- $\theta_{e}$ air $(\geq 356 \mathrm{~K})$ formed rapidly by $1400 \mathrm{LST}$, in vast areas over the landmass to the south of the frontal bands. As recognized from the high value of the surface-level heat flux (1400 LST of Fig. 8c), it is certain that the formation of high- $\theta_{e}$ air resulted from the supply of heat and moisture from the continental surface. During the nighttime (2000-0800 LST), the high- $\theta_{e}$ air was transported to the rainband (Fig. 8b), due to the prevalence of the southwesterly flow (Fig. 8c). The high- $\theta_{e}$ air nearly disappeared by 0800 LST, but the generation of this air resumed in the daytime, with the revival of the heat flux over land, as shown in the last panel of Fig. 8c. The continuous supply of the high $\theta_{e}$ air, due to the southwesterly flow on the southern side of the front, is comparable to that from the observation (Fig. 5) and reanalysis data (Fig. 7). Therefore, it is clear that the control simulations qualitatively reproduced the generation of high- $\theta_{e}$ air and the evolution of the convective rainband, without contradicting the observational evidence.

To examine the reproducibility from a quan- titative viewpoint, the horizontal distribution of rainfall, simulated in the coarse-mesh control experiment, is shown in Fig. 9. The rainfall accumulated for 20 hours from 1800 LST 4 July, and was compared with the observed one in Anhui Province. The results show that the control experiment reproduced a peak of rain $(321.6 \mathrm{~mm})$ near the eastern boundary of Anhui Province. This peak value is comparable with the observed one $(380 \mathrm{~mm}$ at Chuzhou, Fig. 3b). Although the location of the peak was $70 \mathrm{~km}$ south of the observed peak, this discrepancy is nearly negligible because the horizontal grid spacing of the reanalysis data (used for the initial fields and lateral boundary conditions) is $20 \mathrm{~km}$.

The process of rainband formation on the afternoon of 4 July is described in detail, using the result of the fine-mesh control simulation (Fig. 10). The low-level flow before the evolution (1200 LST) was characterized by a line of weak confluence (shown by a dotted line) between southwesterly and west-southwesterly on the lee side of the Dabie Mountains. This line corresponds to the observed shearline (shown in Fig. 5a). Until 1400 LST, the high- $\theta_{e}$ area extended rapidly on the southern side of the shearline, and the meridional gradient of $\theta_{e}$ became sharp along the shearline. As written above, the heat flux from the land surface was responsible for the increase in $\theta_{e}$. After that, the rainband, consisting of cells of hydrometeors larger than $2.0 \mathrm{~g} \mathrm{~kg}^{-1}$, began to develop along the shearline (Fig. 10c). This rain- 


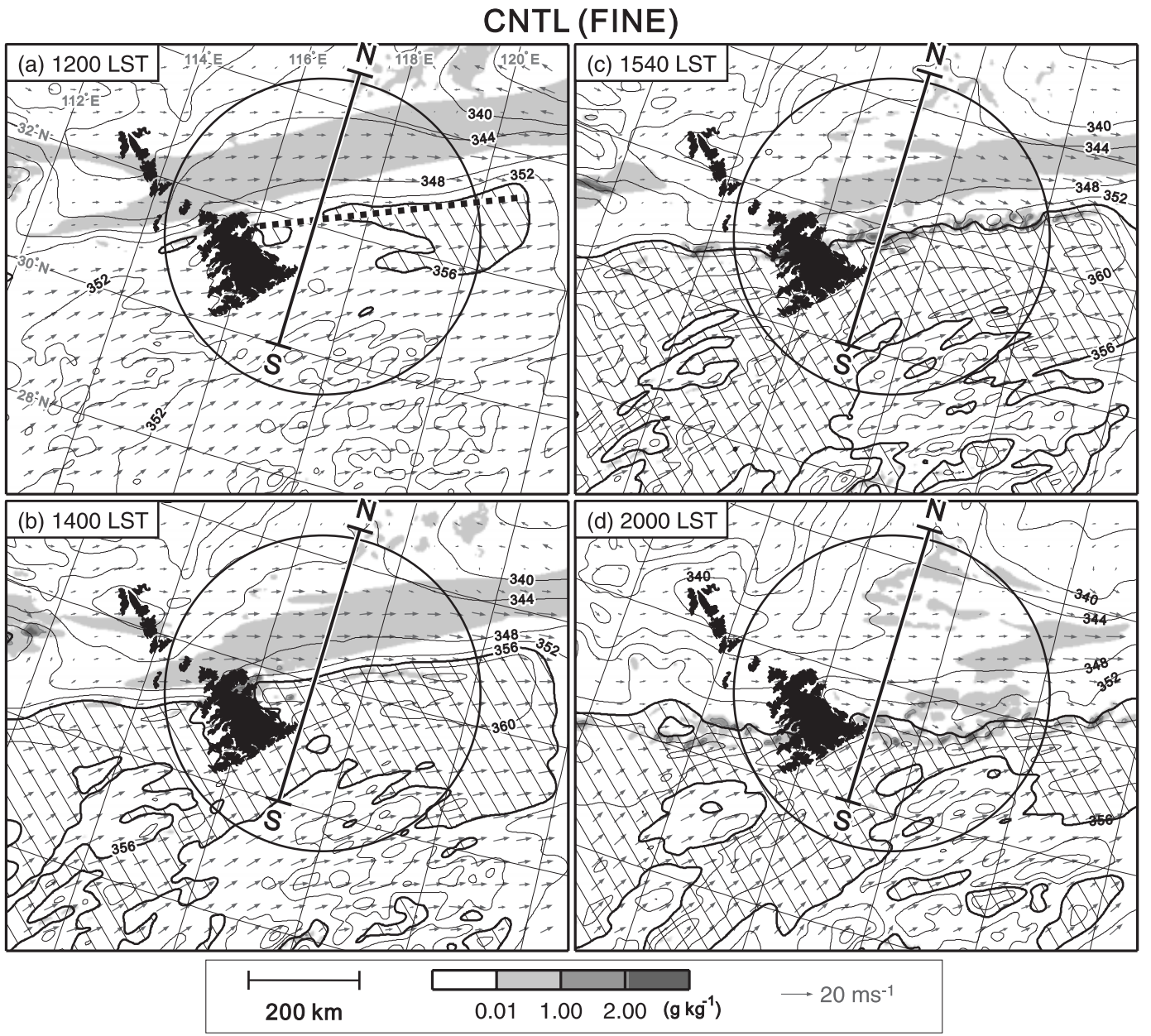

Fig. 10. Horizontal distributions of the hydrometeor mixing ratio (shade), $\theta_{e}$ (contour), and wind vector of the fine-mesh control experiment at $0.5 \mathrm{~km}$ above the ground level. Areas of $\theta_{e}$ higher than $356 \mathrm{~K}$ are hatched and surrounded with a bold line. Topography of the Dabie Mountains higher than $250 \mathrm{~m}$ ASL are painted black. A dotted line in (a) indicates a shearline.

band formed at first on the lee side, extended upwind (Fig. 10d), and remained until the next day (not shown).

The relationship between the high- $\theta_{e}$ air and the rainband evolution is described using vertical sections along the $\mathrm{S}-\mathrm{N}$ line, as shown in Fig. 11. The high- $\theta_{e}$ area (highlighted by a balloon in Fig. 11a) formed near the surface in the southern part, and the top of this area rose to $1 \mathrm{~km}$ ASL near the shearline (marked by a white arrow) by 1400 LST. This rising corresponds to the rapid extension at the horizontal section (described above), and indicates that high- $\theta_{e}$ air accumulated above the shearline due to the horizontal convergence. From 1540
LST (Fig. 11c), the convective rainband began to develop over the shearline. The depth of the rainband reached $16 \mathrm{~km}$ ASL at $2000 \mathrm{LST}$. The magnified vertical sections of airflow and TKE in the vicinity of the shearline are shown in Fig. 12. At 1400 LST, a shallow cloud, with TKE larger than $2.5 \mathrm{~m}^{2} \mathrm{~s}^{-2}$, developed above the rising $356-\mathrm{K}$ contour (bold solid line). This corresponds to shallow cumulus clouds penetrating the top of the boundary layer, which resulted from the accumulation of high- $\theta_{e}$ air over the shearline. This shallow convection grew deeper in the rainband until 1540 LST. It is noteworthy that the low-level southerly inflow began to be reinforced after the formation of 


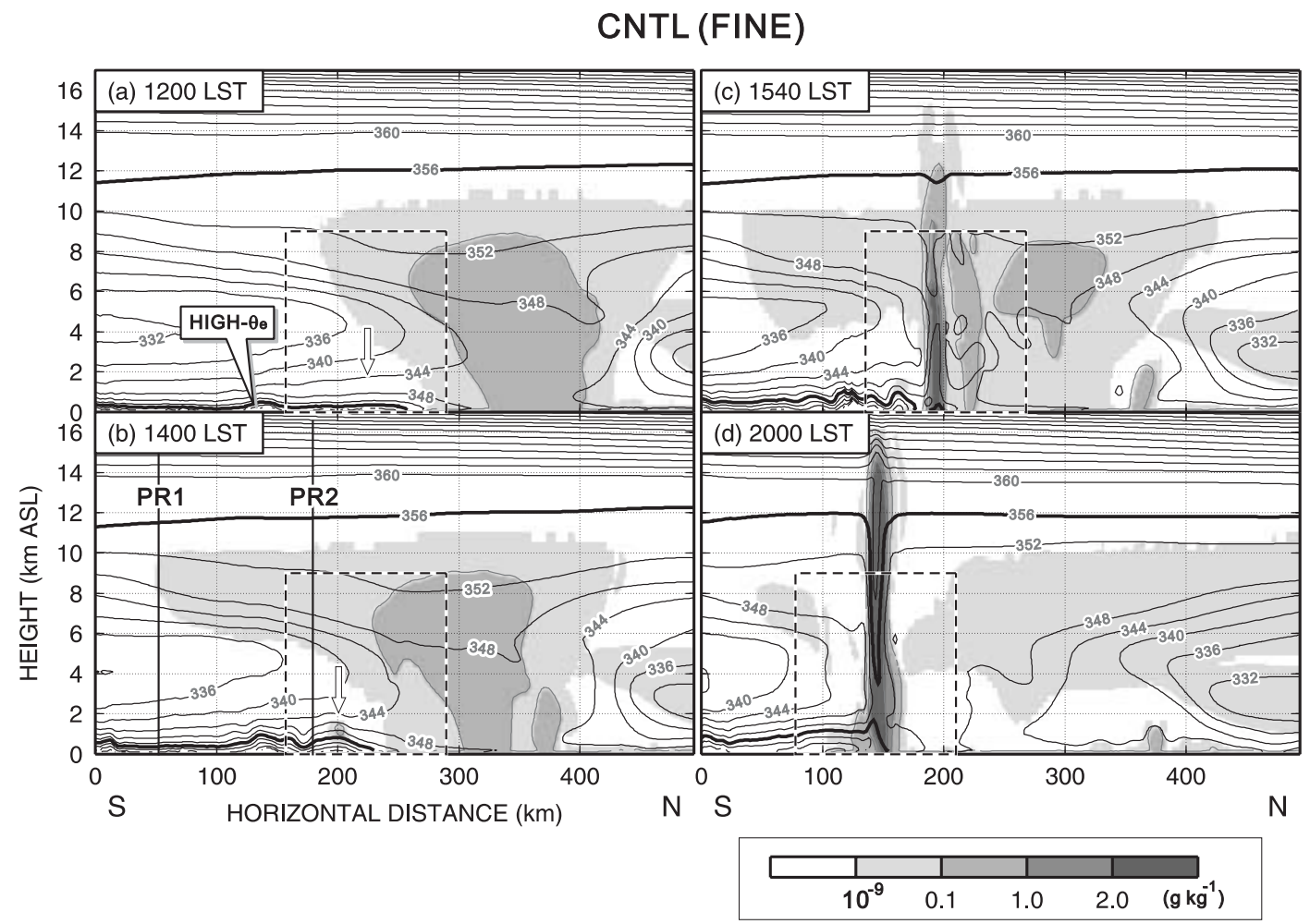

Fig. 11. Vertical sections of the hydrometeor mixing ratio (shade) and $\theta_{e}$ (contour, every $4 \mathrm{~K}$ ) along the S-N line shown in Fig. 10. The contours of $356 \mathrm{~K}$ are highlighted with a bold solid line. White arrows in (a) and (b) indicate the location of a shearline. A box outlined by a broken line in each panel shows the area displayed in Fig. 12.

the rainband (Fig. 12c), and became much stronger, especially near the surface, as the rainband developed (Fig. 12d). The speed of the horizontal component at $0.5 \mathrm{~km}$ ASL was $4 \mathrm{~ms}^{-1}$ at $1400 \mathrm{LST}$, and increased to $9 \mathrm{~ms}^{-1}$ at 2000 LST. This acceleration of horizontal wind reflects the development of low pressure (not shown) below a deep updraft, and indicates a feedback effect of deep convection on the enhancement of convergence along the shearline, as discussed in Kato (1998).

The vertical thermodynamic profile over the point "PR1" (shown in Fig. 11b, the same location as Anqing) at 1400 LST is shown in Fig. 13a. This profile shows large latent instability (1598 J. $\mathrm{kg}^{-1}$ of CAPE), with LFC and LNB at 1.1 and $14.1 \mathrm{~km}$ ASL, respectively. This instability resulted from an increase in the $\theta_{e}$ near the surface. The simulated profile was comparable with the observational one shown in Fig. $6 \mathrm{a}$, except for the simulated LFC, which was about $1 \mathrm{~km}$ lower than that in the observed profile. The stratification was also latently unstable at "PR2" (profile not shown, the location is shown in Fig. 11b) where the CAPE was $1935 \mathrm{~J} \cdot \mathrm{kg}^{-1}$. The time-height cross section of $\theta_{e}$, LFC, and LNB over PR1 is shown in Fig. 13b. This cross section shows that the control simulation reproduced the descent of LFC in the daytime of 4 July and the continuation of low LFC until the next day, which are similar to the observational evidence (Fig. 6b). The continuous supply of high- $\theta_{e}$ air near the surface is also reproduced well. It is clear that the continuation of unstable conditions from 4 through 5 July was responsible for the longlasting convective rainband. The time series of the heat fluxes, downward longwave radiation, and $\theta_{e}$ over the surface at PR1 (Fig. 14) show that the supply of sensible and latent heat fluxes from the surface was the origin of high$\theta_{e}$ air. The almost stable situation of $\theta_{e}$, between 14 and 23 LST, implies that high- $\theta_{e}$ air formed in the vast fine-weather area and was 
CNTL (FINE)

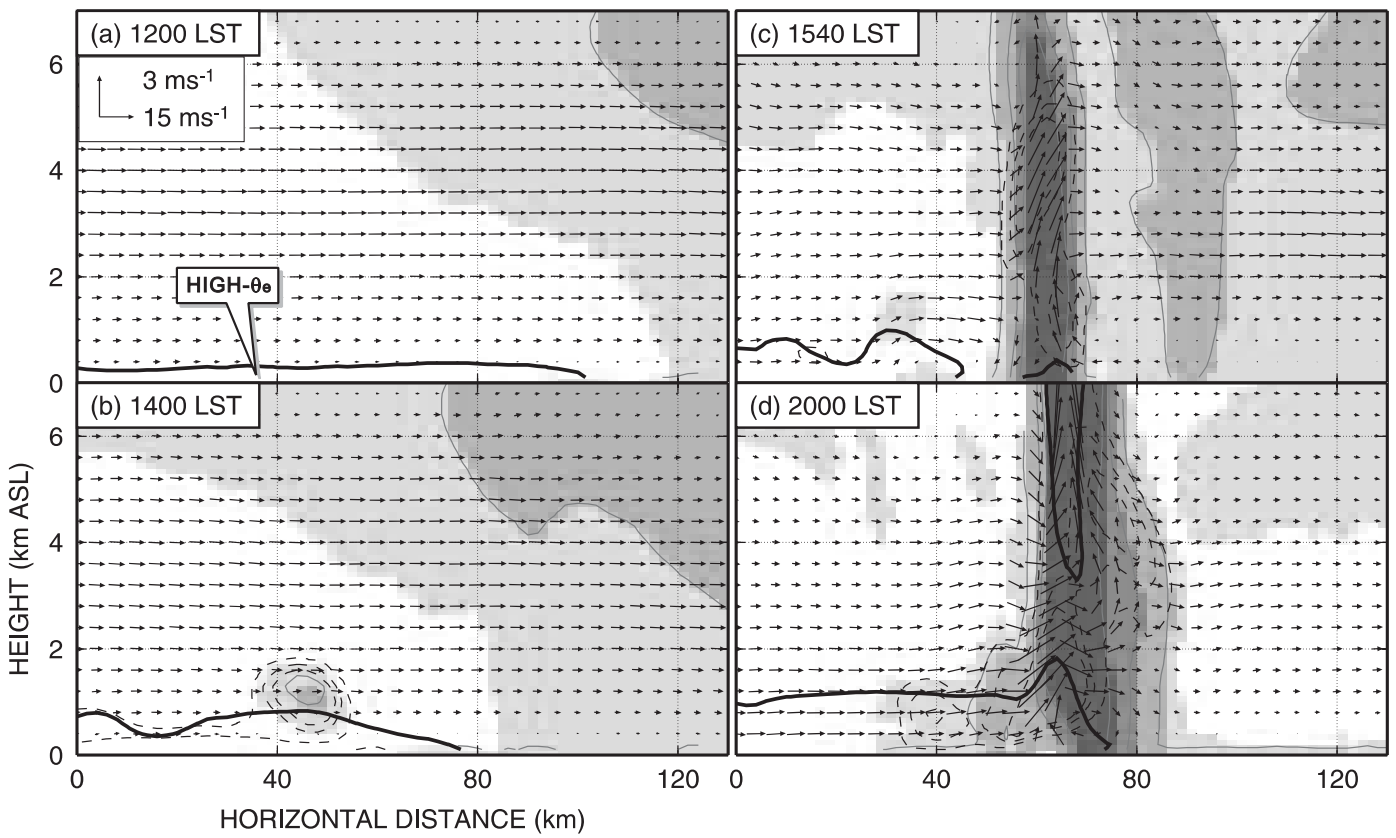

Fig. 12. Vertical sections of the hydrometeor mixing ratio (shade), wind vectors, and TKE (broken contour, at $0.5,1.5$, and $2.5 \mathrm{~m}^{2} \mathrm{~s}^{-2}$ ) within the box shown in Fig. 11. Bold lines indicate the 356-K contour of $\theta_{e}$.

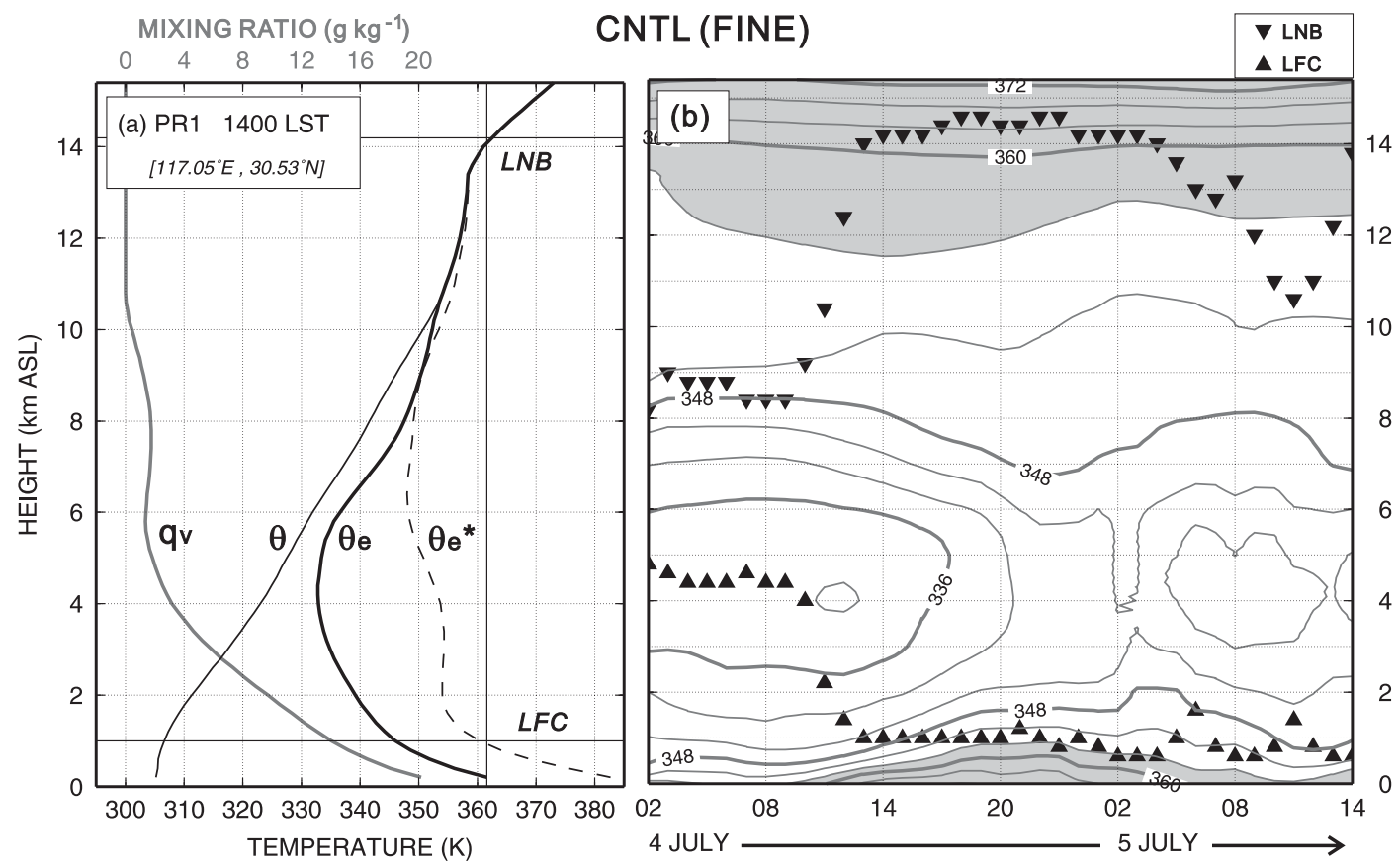

Fig. 13. (a) Vertical profiles of the simulated $q_{v}, \theta, \theta_{e}$, and $\theta_{e}^{*}$ at PR1 (shown in Fig. 11) in the control experiment. (b) Time-height section of the $\theta_{e}, \mathrm{LFC}$, and LNB at the same point. 


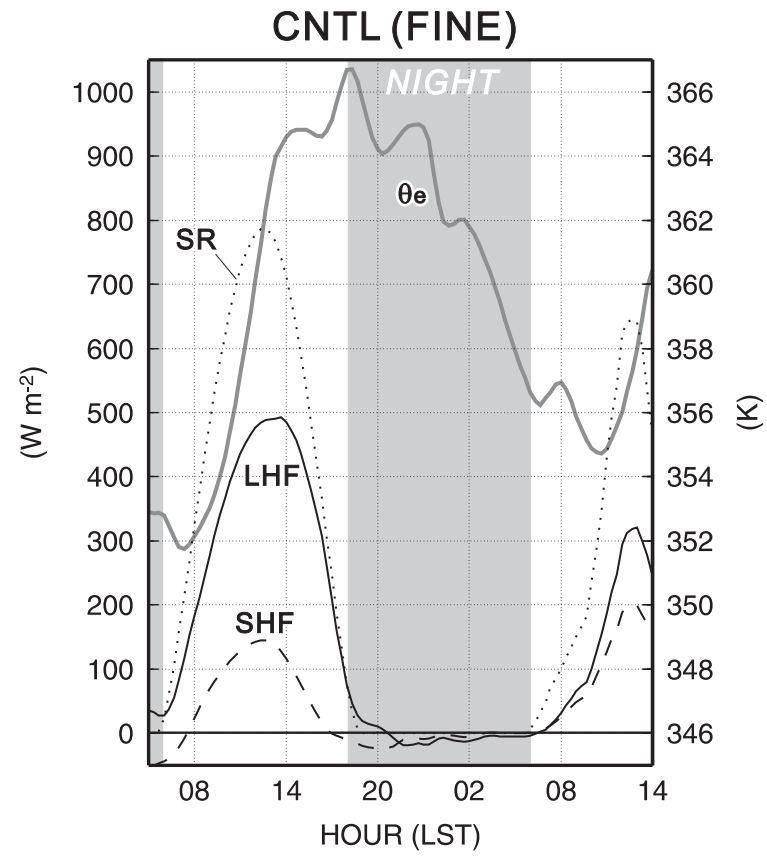

Fig. 14. Time series of the sensible and latent heat fluxes (SHF, LHF), downward shortwave radiation (SR), and equivalent potential temperature $\left(\theta_{e}\right)$ at PR1 shown in Fig. 11.

continually transported over PR1 until midnight. As in the Y07 case, the latent heat was much larger than the sensible heat due to the wet surface conditions (mostly paddy fields), and the daytime maximum of these values (under the cloud free conditions) roughly corresponded to the results of previous observations (Shinoda and Uyeda 2002).

Therefore, in summary, the control simulation reproduced the convective rainband without contradicting the observational evidence. The evolution of the rainband resulted from the latent instability over the frontal zone, due to the inflow of the warm and moist air near the surface. The origin of the warm and moist air was the surface heat flux over the vast fine-weather area to the south of the front in the daytime. The long duration of the rainband resulted from the continuous supply of high $-\theta_{e}$ air throughout the night.

\section{Sensitivity experiments}

While the control simulation successfully reproduced the evolution of the rainband causing heavy rainfall, there are three questions that need to be clarified. The first one is the role of synoptic-scale convergence in the lower troposphere, which can create upward motion and may affect the rainband evolution. The second is the role of the topography, which can disturb the mesoscale flow structure in the lower troposphere and change the rainfall distribution. The importance of the convergence and topography is examined by performing the NoSR and NoTR experiments, respectively. The last question is the dependency of rainfall duration on the horizontal extent of the heated landmass. As described in Section 3, the rainband examined in this study lasted much longer than that studied in Y07. Since the area of fine weather in southern China in the present case was considerably larger than that in the Y07 case, it is possible that the horizontal extension of the heated area was related to the rainband duration. This question can be clarified through the ChLU1-3 experiments.

\section{a. NoSR (no shortwave radiation) experiment}

The results of the fine-mesh NoSR experiment are shown in Fig. 15. The horizontal distributions (Figs. 15a and b) show that the weak rainfall band and the shearline were reproduced well at $1400 \mathrm{LST}$, but that the convective rainband was not reproduced at $2000 \mathrm{LST}$. The vertical sections, along the $\mathrm{S}-\mathrm{N}$ line (Figs. $15 \mathrm{c}$ and $\mathrm{d}$ ), show a complete lack of the convective rainband and the maintenance of weak rainfall. A principal cause of the failure was the lack of latent instability in the environment. The $\theta_{e}$ near the surface was, at most, $348 \mathrm{~K}$ in the south of the shearline, which was almost the same as the minimum value of the saturated equivalent potential temperature $\left(\theta_{e}^{*}\right)$ near $6 \mathrm{~km}$ ASL. Of course, the lack of high- $\theta_{e}$ air resulted from the exclusion of solar radiation and surface heating. As a result of the absence of a convective rainband, the accumulation of rainfall for 20 hours (Fig. 16a) was very small, with a peak of $114.9 \mathrm{~mm}$ to the east of Anhui Province. This weak rainfall was brought from the weak rainfall band, that lasted throughout the simulated period. Therefore, the results of the NoSR experiment demonstrate that the convective rainband was never generated without strong latent instability due to the surface heating, even if a synoptic-scale convergence was present over a front. 

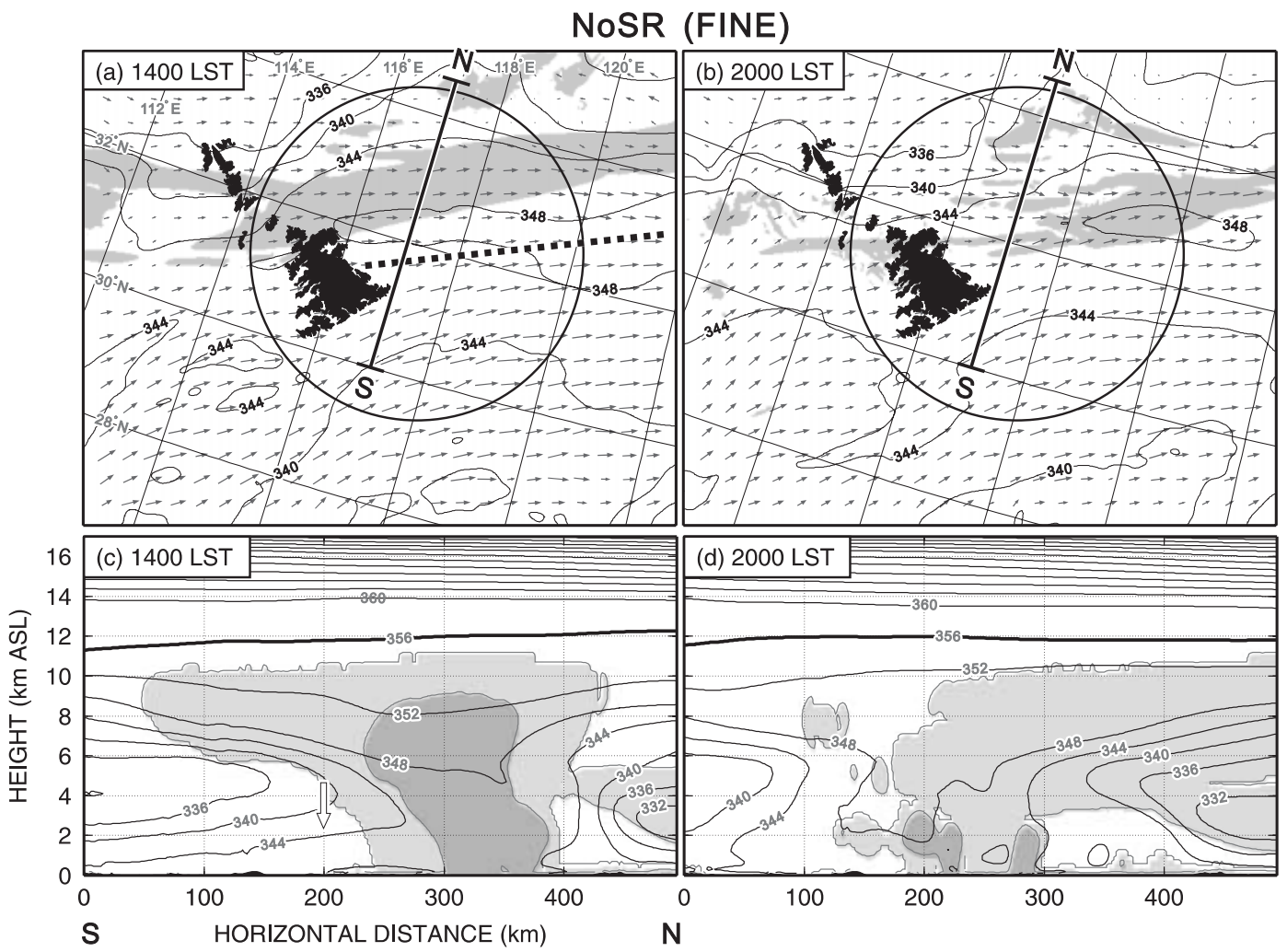

Fig. 15. Results of the experiment without solar radiation (NoSR). (a and b) The same variables are shown in the same form as in Fig. 10, and (c and d) Fig. 11.

This indicates that the heated land surface plays a crucial role in the evolution of the convective rainband, as it did in the Y07 case.

\section{b. NoTR (no terrain) experiment}

Since the NoTR experiment included the process from the land-surface heating through the latent instability over the front, this experiment reproduced a long-lasting convective rainband. Thus, this simulation was compared with the control experiment, using the distribution of rainfall accumulated for 20 hours (Fig. 16b). The overall distribution shows that a long band of rainfall was reproduced at almost the same place as in the control simulation (Fig. 9). This means that the meridional position of the front, is not greatly changed by the topography over the continent, and is almost controlled by the synoptic-scale flow structure. However, it is noteworthy that the position of the local rainfall maxima, in the NoTR experiment, was greatly changed from that in the control experiment. The peak near the eastern border of An- hui Province moved eastward to the coastal area. The value of the peak was $277.2 \mathrm{~mm}$, which was $86 \%$ of the amount in the control experiment, but with better reproducibility than that in the NoSR experiment. Another peak in the western slope of the Dabie Mountains, which was reproduced in the control experiment, was not remarkable in the NoTR experiment. This suggests the importance of the topography for the position of rainfall peaks along the front, through the modification of the flow structure in the lower troposphere. This result also suggests that heavy rainfall may occur somewhere along the front even if there are no mountains over the landmass. It is, therefore, clear that the importance of the topography, for the heavy rainfall, was secondary to that of the land-surface heating, from the perspective of the synoptic scale.

\section{c. ChLU (changed land-use) experiments}

As described in Section 2, and shown in Fig. 2 , the meridional width of the area heated 
20-HR RAINFALL ( $\mathrm{mm}, 18-14$ LST)
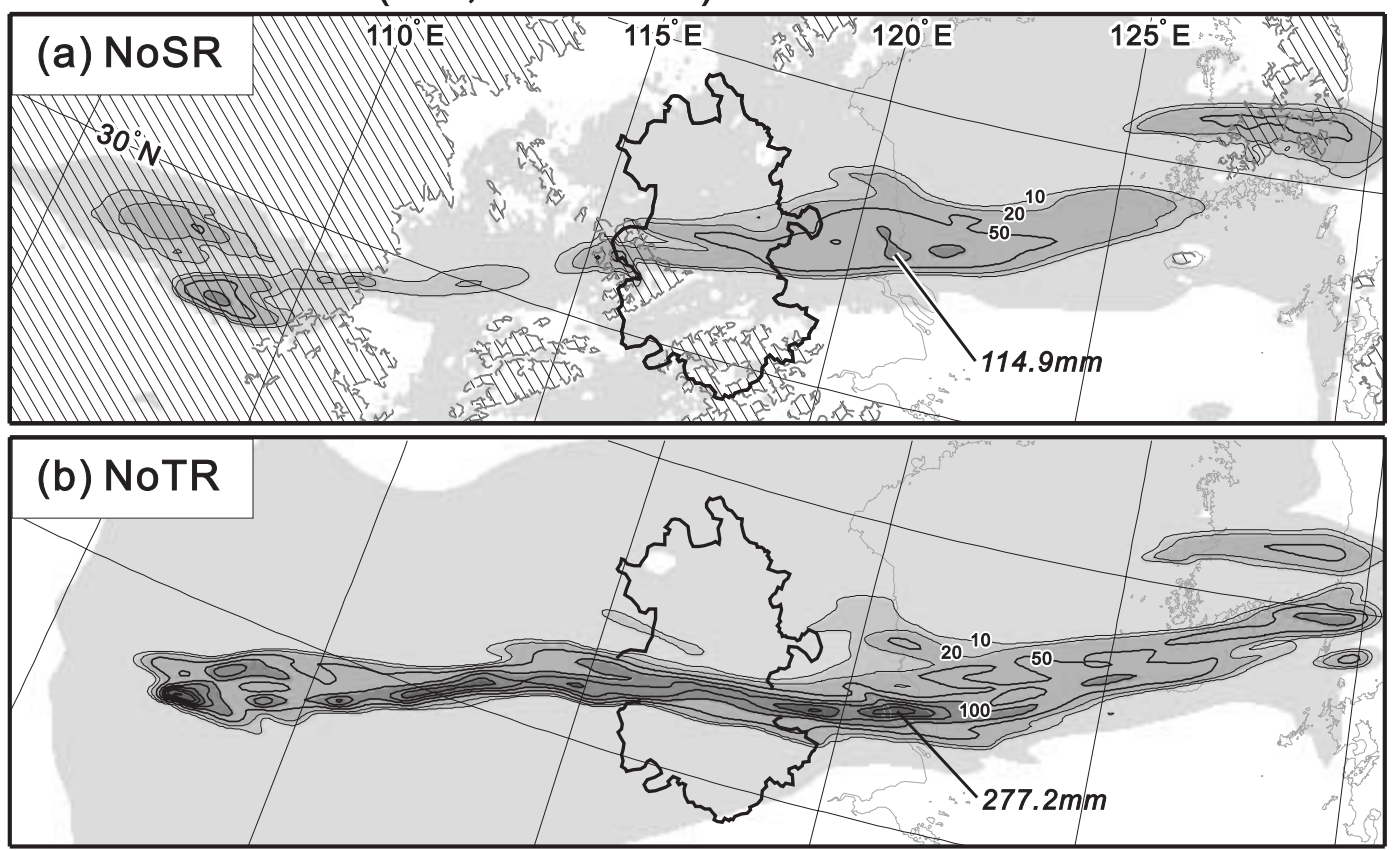

Fig. 16. The same as Fig. 9, but for the experiments (a) without shortwave radiation (NoSR) and (b) without terrain (NoTR).

by solar radiation to the south of the front is the narrowest in ChLU1, and the widest in ChLU3. The influence of this width to the duration of the rainband is examined, using the experiment of the ChLU series. Figure 17 shows the time-latitude sections of the rainfall intensity at the surface and the $\theta_{e}$ at $0.5 \mathrm{~km}$ AGL. These values were averaged zonally between 117.0 and $118.5^{\circ} \mathrm{E}$, corresponding to the zonal range of the heavy rainfall area (see Fig. 3a). The results of the ChLU series, and those of the control and NoSR experiments are shown, and they are arranged according to the meridional width of the heated area. In all experiments, except for NoSR, the high- $\theta_{e}$ area began to appear in the daytime of the first day. The duration of the high- $\theta_{e}$ air supply varied according to the meridional width of the heated area: 8 hours in the ChLU1 experiment, and 20 hours in ChLU3. Rainfall heavier than $20 \mathrm{~mm} \mathrm{hr}^{-1}$ began nearly 6 hours later than the appearance of high- $\theta_{e}$ air. It is noteworthy that the heavy rain ended within a few hours of the disappearance of high- $\theta_{e}$ air in the ChLU1 and ChLU2 experiments, but remained in ChLU3, as it did in the control experiment. This result indicates that the rainband duration depended on the duration of high- $\theta_{e}$ air supply that is controlled by the meridional extent of the heated land surface. By using the meridional width of the heated surface $(\Delta y)$ and the meridional wind component ( $v$ : $6 \mathrm{~ms}^{-1}$ ) averaged below $1 \mathrm{~km}$ ASL, the duration of high- $\theta_{e}$ air supply can be represented simply as follows,

$$
t=\Delta y / v \text {. }
$$

The duration of heavy rainfall is several hours shorter than $t$.

In summary, a series of sensitivity experiments demonstrated that the rainband was not reproduced when the surface heating effect was excluded. The dependency of the rainband duration on the meridional width of the heated area was also demonstrated. These results were evidence that land-surface heating over fine-weather areas to the south of the front is essential for the rainband evolution and its duration. 


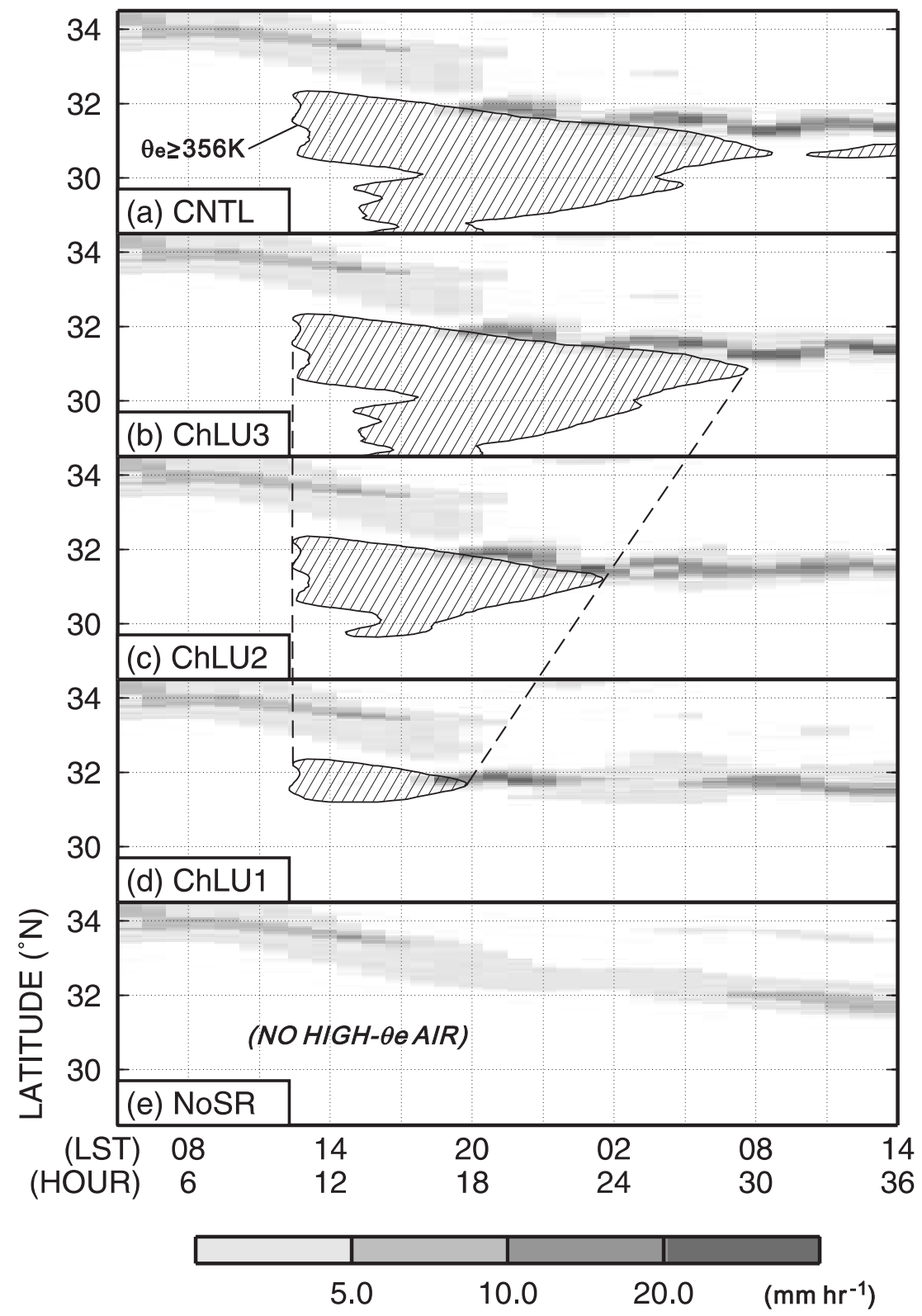

Fig. 17. Time-latitude sections of the hydrometeor mixing ratio and the $356-\mathrm{K} \theta_{e}$ contour at $0.5 \mathrm{~km}$ above the ground level in the control and sensitivity experiments.

\section{Discussion}

Through a series of numerical simulations, this study has demonstrated the role of a heated landmass on the evolution and maintenance of a heavy overnight rainfall. The relevance of this study to previous ones, on nocturnal heavy rainfall resulting from MCSs, is discussed here. As mentioned in the introduc- tion, heavy rainfall sometimes occurs, not only over mainland China, but over the central United States in summer. Wallace (1975) hypothesized that there are thermodynamic and dynamic factors responsible for the nocturnal evolution. The former is the land-surface heating in the daytime, which contributes to the latent instability that is the focus of the present study. The latter is the surface friction that 
causes diurnal variability in the strength of a low-level jet, and contributes to the variation of convergence over a synoptic-scale frontal zone. Many studies have addressed the mechanism of a low-level jet and the effect in the nocturnal MCSs evolution (e.g., Augustine and Caracena 1994). Over mainland China, Li et al. (2007) examined the role of LLJ on the nocturnal evolution of MCS in the 1998 summer. However, what must be remembered is that deep convection never occurs without latent instability, even when convergence is present, as demonstrated in the NoSR experiment of the present study. In other words, LLJ can act as a trigger of deep convection only when LLJ transports warm and moist air, which is required for latent instability over a convergence zone. Therefore, the combination of LLJ (i.e., dynamic factor) with high- $\theta_{e}$ air (thermodynamic factor) is necessary for the nocturnal MCS evolution, and land-surface heating is an important factor causing high- $\theta_{e}$ air. The combination and its relationship with the nocturnal MCS evolution, were reported as observational evidence (Trier and Parsons 1993). From a climatological viewpoint, the importance of the combination was recently suggested by Segal et al. (2002), using a regional climate model with a 12-hour solar shift. The present study has demonstrated the significance of this, in a case of heavy rainfall over China, through an observation and a series of simulations using a cloud-resolving model.

In East Asia, heavy rainfall resulting from MCSs over a Meiyu front occurs not only over mainland China but over oceanic areas, such as Japan and Taiwan. There is a remarkable difference in the cloud distribution between the continental and oceanic areas, as reported by Ninomiya (1989). Instead of the continental surface, a vast ocean surface is probably responsible for the source of heat and moisture, although its importance has rarely been the focus of studies. The process of latent instability over oceanic areas is probably quite different from that over the continent, owing to the following three factors. First, the diurnal variation of sea surface temperature (SST) is usually smaller than that of land-surface temperature. Secondly, the vertical mixing of oceanic water can significantly change the SST. Lastly, the ocean currents, such as the Kuroshio current in the Pacific ocean, can transport warm water from a tropical region. Therefore, it is necessary to clarify the dynamic and thermodynamic processes coupled between the atmosphere and ocean, in order to understand the formation process of warm and moist air over the ocean. As speculated in Kato et al. (2003), warm and moist air does not distribute uniformly, but has horizontal extent of several hundred kilometers to the south of a MeiyuBaiu front. The process for the formation of a mass of warm and moist air has not been explained. Mesoscale observations and numerical simulations on the ocean-atmosphere interaction in the south of Japan are thus, necessary for further understanding of the MCS evolution over the Meiyu-Baiu front.

\section{Summary}

This paper describes the results of intensive field experiment and a series of numerical simulations on a heavy rain episode over mainland China. The case studied was a long-lived convective rainband, forming over the Yangtze River basin, and brought heavy rainfall reaching $380 \mathrm{~mm}$ in 20 hours on 4-5 July 2003 . The principal purpose of this study was to demonstrate the role of the heated continental surface on the evolution and duration of a heavy rain episode. While the impact of a heated surface was demonstrated in our previous case study (i.e., Y07), the present study applies a similar idea to another case with different synoptic-scale conditions, to demonstrate the general importance of surface heating on the MCS evolution over land. The simulations using the Nagoya University Cloud Resolving Storm Simulator (CReSS) were performed within a domain covering central and southern China, to reproduce land-surface heating to the south of the front. Sensitivity experiments without shortwave radiation, without terrain, and with modified land-surface conditions, were conducted to examine the factors at play in the evolution and duration of the rainband.

Observational evidence showed that a heavy rain episode resulted from a long-lasting convective rainband over a stationary front. The synoptic-scale situations were characterized by a southerly inflow in the lower troposphere, and no marked meandering of the upper-level flow. The vast area of fine weather to the south 
of the front, under the prevalence of a subtropical high, was also important background. The control simulation reproduced the rainband, and its reproducibility was good in comparison to the observational evidence. The evolution resulted from the latent instability due to the inflow of the warm and moist air from the fineweather area to the south of the front. The origin of the warm and moist air was the surface heat flux over the vast fine-weather area to the south of the front in the daytime. The longlasting rainband resulted from the continuous supply of high $-\theta_{e}$ air throughout the night. The sensitivity experiments demonstrated that the rainband was never reproduced without latent instability due to surface heating. It was also demonstrated that the duration of heavy rain can be represented as a function of the meridional width of the heated area and meridional velocity component in the lower troposphere.

It is, therefore, concluded that land-surface heating over the fine-weather areas to the south of a Meiyu-Baiu front is a crucial factor for the evolution and duration of a convective rainband. It is suggested that land-atmospheric interaction is a key process for the nocturnal evolution of MCS over the continental plains in summer. It is also suggested that the meridional width of a fine-weather area to the south of a stationary front is a useful parameter for predicting the duration of a heavy rain episode.

\section{Acknowledgments}

The authors express their thanks to Prof. Y. $\mathrm{Ni}$, and Dr. L. Liu of the Chinese Academy of Meteorological Sciences for their cooperation in the field experiment and for supplying the data. Thanks are also due to Dr. T. Kikuchi of Kochi University, for use of the GOES images. Thanks are also extended to Dr. M. Yoshizaki of IORGC, JAMSTEC, Dr. M. Murakami, and the anonymous reviewers for their constructive criticisms and helpful comments.

\section{References}

Akiyama, T., 1984: A medium-scale cloud cluster in a Baiu front. Part I: Evolution process and fine structure. J. Meteor. Soc. Japan, 62, 485-504.

Anderson, C.J. and R.W. Arritt, 1998: Mesoscale convective complexes and persisted elongated convective systems over the United States during 1992 and 1993. Mon. Wea. Rev., 126, 578-599.
Augustine, J.A. and F. Caracena, 1994: Lowertropospheric precursors to nocturnal MCS development over the central United States. Wea. Forecasting, 9, 116-135.

Bosart, L.F. and F. Sanders, 1981: The Johnstown flood of July 1977: A long-lived convective system. J. Atmos. Sci., 38, 1616-1642.

Brooks, H.E. and D.J. Stensrud, 2000: Climatology of heavy rain events in the United States from hourly precipitation observations. Mon. Wea. Rev., 128, 1194-1201.

Chen, S.-J., Y.-H. Kuo, W. Wang, Z.-Y. Tao, and B. Cui, 1998: A modeling case study of heavy rainstorms along the Meiyu front. Mon. Wea. Rev., 126, 2330-2351.

Ding, Y., 1992: Summer monsoon rainfalls in China. J. Meteor. Soc. Japan, 70, 373-396.

Geng, B., H. Yamada, K.K. Reddy, H. Uyeda, and Y. Fujiyoshi, 2004: An observational study of the development of a rainband on a Meiyu front causing heavy rainfall in the downstream region of the Yangtze River. J. Meteor. Soc. Japan, 82, 1095-1115.

Ikebuchi, S., M. Shiiba, Y. Tachikawa, and K. Tanaka, 1998: Observation and modeling of landsurface fluxes in HUBEX. Preliminary research report on Japanese GAME/HUBEX, 364-388.

Kato, T., 1998: Numerical simulation of the bandshaped torrential rain observed over southern Kyushu, Japan on 1 August 1993. J. Meteor. Soc. Japan, 76, 97-128.

Kato, T., M. Yoshizaki, K. Bessho, T. Inoue, Y. Sato, and X-BAIU-01 observation group, 2003: Reason for the failure of the simulation of heavy rainfall during X-BAIU-01-Importance of a vertical profile of water vapor for numerical simulations-. J. Meteor. Soc. Japan, 81, 9931013.

Laing, A.G. and J.M. Fritsch, 2000: The large-scale environments of the global populations of mesoscale convective complexes. Mon. Wea. Rev., 128, 2756-2776.

Li, Z., T. Takeda, K. Tsuboki, K. Kato, M. Kawashima, and Y. Fujiyoshi, 2007: Nocturnal evolution of cloud clusters over eastern China during the intensive observation periods of GAME/ HUBEX in 1998 and 1999. J. Meteor. Soc. Japan, 85, 25-45.

Ninomiya, K., 1989: Cloud distribution over East Asia during Baiu period of 1979. J. Meteor. Soc. Japan, 67, 639-658.

Ninomiya, K., 2000: Large- and meso- $\alpha$-scale characteristics of Meiyu/Baiu front associated with intense rainfalls in 1-10 July 1991. J. Meteor. Soc. Japan, 78, 141-157.

Ninomiya, K. and Y. Shibagaki, 2003: Cloud system 
families in the Meiyu-Baiu front Observed during 1-10 July 1991. J. Meteor. Soc. Japan, 81, 193-209.

Ninomiya, K., T. Akiyama, and M. Ikawa, 1988: Evolution and fine structure of a long-lived meso- $\alpha-$ scale convective systems in a Baiu frontal zone. Part I: Evolution and meso- $\beta$-scale characteristics of precipitation. J. Meteor. Soc. Japan, 66, 331-350.

Reynolds, R., N. Rayner, T. Smith, D. Stokes, and W. Wang, 2002: An improved in-situ and satellite SST analysis for Climate. J. Climate, $\mathbf{1 5}$, 1609-1625.

Schumacher, R.S. and R.H. Johnson, 2005: Organization and environmental properties of extreme-rain-producing mesoscale convective systems. Mon. Wea. Rev., 133, 961-976.

Schumacher, R.S. and R.H. Johnson, 2006: Characteristics of U.S. extreme rain events during 1999-2003. Wea. Forecasting, 21, 69-85.

Segal, M., Z. Pan, and R.W. Arritt, 2002: On the effect of relative timing of diurnal and largescale forcing on summer extreme rainfall characteristics over the central United States. Mon. Wea. Rev., 130, 1442-1450.

Segami, A., K. Kurihara, H. Nakamura, M. Ueno, I. Takano, and Y. Tatsumi, 1989: Operational mesoscale weather prediction with Japan Spectral Model. J. Meteor. Soc. Japan, 67, 907-924.

Shinoda, T. and H. Uyeda, 2002: Effective factors in the development of deep convective clouds over the wet region of Eastern China during the summer monsoon season. J. Meteor. Soc. Japan, 80, 1395-1414.

Shinoda, T., H. Uyeda, and K. Yoshimura, 2005: Structure of moist layer and sources of water over the southern region far from the Meiyu/ Baiu front. J. Meteor. Soc. Japan, 83, 137-152.
Takeda, T. and H. Iwasaki, 1987: Some characteristics of meso-scale cloud clusters observed in East Asia between March and October 1980. J. Meteor. Soc. Japan, 65, 507-513.

Trier, S.B. and D.B. Parsons, 1993: Evolution of environmental conditions preceding the development of a nocturnal mesoscale convective complex. Mon. Wea. Rev., 121, 1078-1098.

Tsuboki, K. and A. Sakakibara, 2002: Large-scale parallel computing of cloud resolving storm simulator. High Performance Computing, H.P. Zima et al., Eds., Springer, 243-259, http:// www.rain.hyarc.nagoya-u.ac.jp/ tsuboki/src/ pdf_research/ishpc2002_tsuboki.pdf.

Wallace, J.M., 1975: Diurnal variations in precipitation and thunderstorm frequency over the conterminous United States. Mon. Wea. Rev., 103, 406-419.

Wang, C.-C., G.T.-J. Chen, T.-J. Chen, and K. Tsuboki, 2005: A numerical study on the effects of Taiwan topography on a convective line during the Mei-Yu season. Mon. Wea. Rev., 133, 32173242 .

Yamada, H., B. Geng, K.K. Reddy, H. Uyeda, and Y. Fujiyoshi, 2003: Three-dimensional structure of a mesoscale convective system in a Baiufrontal depression generated in the downstream region of the Yangtze River. J. Meteor. Soc. Japan, 81, 1243-1271.

Yamada, H., B. Geng, H. Uyeda, and K. Tsuboki, 2007: The thermodynamic impact of the heated landmass on the nocturnal evolution of a cloud cluster over a Meiyu-Baiu front. J. Meteor. Soc. Japan, 85, 663-685.

Yamasaki, M., 2005: A numerical study of cloud clusters and a meso- $\alpha$-scale low associated with a Meiyu front. J. Meteor. Soc. Japan, 83, 305329. 